\title{
Government Outsourcing: Public Contracting with Private Monopoly
}

\author{
Emmanuelle Auriol ${ }^{1}$ and Pierre M. Picard ${ }^{2}$
}

June 13 th $2008^{3}$

\begin{abstract}
The paper studies the impact of government budget constraint on the regulation of natural monopolies in adverse selection contexts. The government maximizes total surplus but incurs some cost of public funds à la Laffont and Tirole (1993). Government outsourcing is proposed as an alternative to regulation in which firms freely enter the market and choose their prices and output levels. However the government can contract ex-post with the private firms. This ex-post contracting set-up allows more flexibility than regulation where governments commit to both investment and operation cash-flows. This is especially relevant in case of high technological uncertainties.
\end{abstract}

Keywords: Privatization, soft-budget constraint, adverse selection, regulation, natural monopoly. JEL Classification: L43, L51, D82, L33.

\footnotetext{
${ }^{1}$ TSE (ARQADE and IDEI), Université de Toulouse I, Place Anatole-France, 31042 Toulouse cedex, France.

${ }^{2}$ SoSS,University of Manchester, Oxford Road, Manchester, MP13 9PL, United Kingdom, and CORE, Catholic University of Louvain, Voie du Roman Pays, 1348 Louvain-la-Neuve, Belgium.

${ }^{3}$ The authors thank the editor and the anonymous referees for their useful comments and suggestions. We thank participants at CORE seminar (2005), CEPR ESF Exploratory Workshop (Bristol 2006), CESifo meeting (Munich 2006), and to the IDEI conference on "Health Economics and the Pharmaceutical Industry", (Toulouse 2008). All remaining errors are ours.
} 


\section{Introduction}

Governments have dramatically reduced their scope over the last 20 years. European member states have accepted opening their utilities to EU competitors, which generally implied both deregulating and privatizing several national monopolies. Similarly many former communist countries have implemented massive privatization programs to restructure their economies. Finally the liberalization and privatization movement has occurred in other OECD countries and in many developing countries, generally as part of structural adjustment programs. Economists have undertaken a substantial amount of work to analyze the cost and benefit of the reforms. A consensus emerges that privatization tends to improve firms' performance so that public ownership/provision is generally suboptimal in competitive industries. However, in increasing returns to scale industries, the efficiency gains of privatization are not necessarily transmitted to consumers. ${ }^{4}$ Moving from public to private ownership does not offer a solution to the lack of competition that prevails in sectors such as infrastructure, water and waste management, public transport, mail services, information and communications technology services. Nevertheless the UK, Australia, New Zealand, and to a lesser extent the US, have adopted competitive tendering and outsourcing in many segments of those industries. ${ }^{5}$ This raises the question about the economic rationale for government to contract out in non-competitive markets.

This paper aims to address this question by focusing on government's monitoring of natural monopoly, for which regulation is usually recommended. Government outsourcing is defined as the combination of a transfer of control and cash-flow rights to a private firm and of the possibility of government offering ex-post contracts to it. The paper presents the properties of the optimal ex-post contracts and compares the welfare obtained under

\footnotetext{
${ }^{4}$ For instance the $5 \%$ fall in total generation costs, that is attributed to the UK electricity privatization program, has (at least) initially been captured by the private shareholders (see Newbery and Pollitt 1997).

${ }^{5}$ In the UK, Kable (2006) estimates that the market for public sector outsourcing during the years 2005 and 2006 has reached 49.4 billions of pounds and is expected to grow by $30 \%$ over the next three years to reach an annual spend of 64.3 billions of pounds. Similarly the average American city contracts out almost a quarter of its common municipal services to the private sector, while the average American state contracts out $14 \%$ of its activities (Savas 2005).
} 
regulation and outsourcing. It shows that the outsourcing policy is often better than regulation, even under the ideal assumption that a benevolent government is able to commit to a set of complete contracts.

In the regulation regime, which is based on Baron and Myerson's (1982) model, the utilitarian government decides to set up a regulated firm run by a manager who benefits from private information about the firm's cost. The government has control and cashflow rights over the regulated firm. It controls the investment and production decisions and is therefore accountable for the firm's profits and losses. Such a combination of control rights and accountability duties by the government is typical of public ownership. Under asymmetric information, the government designs incentive contracts to entice the firm's manager to set the efficient level of production at some informational cost. In the outsourcing regime, a private investor is invited to enter the market, possibly in exchange for a franchise fee. ${ }^{6}$ The private investor gets the control and cash-flow rights on the outsourced activity. He/she controls the investment and production decisions and therefore is fully accountable for his/her profits and losses. As it is, the private firm is allowed to set the laissez-faire monopoly prices. Yet, because laissez-faire is not necessarily optimal, the government can improve welfare by offering ex-post contracts to the private firm (i.e., once investment costs have been sunk and uncertainties have been solved). To accept such ex-post contracts, the private investor must at least obtain his/her laissez-faire profit. Technically this implies that the individual rationality constraint of the private investor is type dependent.

The paper contribution is twofold. First of all, it characterizes the optimal outsourcing contracts. In particular it shows that governments offer more selective contracts under outsourcing than under regulation: high cost firms may indeed receive no ex-post contracts. This result can be explained as follows. At the ex-post contracting stage, the private firm knows its cost parameter whereas the government does not. If the government chooses to contract with all types of firms, as it does in the regulation regime, then

\footnotetext{
${ }^{6}$ The franchise fee mights be the result of a competitive tendering or of a bargaining process between the government and private investor (see section 5.3).
} 
incentive considerations apply and lead to a reduction of the output levels of high cost firms. This strategy prevents low cost firms from inflating their cost reports (see Baron and Myerson, 1982). Incentive issues can be so harsh that the output levels of high cost firms become smaller than the output levels that they achieve as laissez-faire monopoly. As a result, consumer surplus can be significantly reduced and the utilitarian government is simply better off without contracting with high cost firms. Second, the paper characterizes the necessary and sufficient condition under which outsourcing is preferred to regulation. The benefit of outsourcing can be broken down into two effects. First, outsourcing can generate a fiscal effect as the government is able to terminate subsidies to money-losing projects and possibly also to collect a franchise fee from the private investor. Second, outsourcing can generate an economic surplus effect as production can be higher under outsourcing than under regulation. When those two effects are large enough outsourcing is optimal.

To assess the practical relevance of this analysis, the paper presents four particular situations under which outsourcing is preferred to regulation. First, when the shadow cost of public funds is small enough (as it is likely to be in advanced economies), outsourcing is optimal as soon as there exists a cost realization for which the firm makes a loss. This occurs in sectors that involve large uncertainties such as high technologies and R\&D intensive industries. As an example, in OECD countries, legal drugs are supplied with the help of partnerships between the public and the private sector. The type of contractual arrangements existing for pharmaceutical products is very close from the ex-post contractual arrangement described in the paper.

Second, when the cost of public funds is very large (as it can be in very poor countries), the government puts much less weight on consumer surplus than on the transfers to and from the firm. Outsourcing takes the extreme form of laissez-faire. The government never offers an ex-post contract to the private firm whereas it runs the regulated firm to maximize its tax proceeds. Outsourcing becomes optimal as soon as the franchise fee paid by the private investor becomes larger than the expected tax proceeds on the regulated firm. This result implies that poor countries should not use public ownership 
and regulation in less profitable market segments. For instance, the services used by SubSaharan African low income populations are many times provided by privately owned, unregulated (and informal) firms (see Auriol and Blanc, 2007).

Third, it is shown that outsourcing is optimal for any costs of public funds if the government is able to obtain enough revenues with ex-ante franchise fees. Outsourcing is hence better than regulation if the franchise fee is the result of a perfectly competitive bidding or of an efficient bargaining process between the government and the private investors. The conditions for efficient bargaining and competitive bidding are more likely to be satisfied in advanced economies. For instance, this might offer an explanation about the outsourcing policy of water management in large French cities.

Finally the paper proposes a full characterization of the outsourcing choice under linear demand functions and uniform cost distributions. This class of examples shows that the set of economic parameters supporting the outsourcing decision is far from negligible. It hence shows that outsourcing is more likely to dominate regulation for stronger technological uncertainty and for lower market profitability. Postal and transportation services in low density areas are good candidates for such low profitability outsourcing contracts.

Related literature The paper relates to the existing literature in several ways. First of all, it belongs to the traditional regulation literature initiated by Baron and Myerson's (1982) and Laffont and Tirole's (1986) models of natural monopoly. However, contrary to these earlier contributions, it does not postulate that regulation is optimal. Indeed over the last 20 years many contributions have pointed out the drawbacks of public management. The literature on deregulation and optimal industry design under incomplete information insists on the point that choosing an industry structure in increasing returns to scale industries is not a trivial issue (see Auriol-Laffont, 1993; Dana and Spier, 1994; McGuire and Riordan, 1995).

Second, the paper is related to the literature on privatization. This literature considers that public firms are less efficient because governments lack economic orientation ${ }^{7}$

\footnotetext{
${ }^{7}$ For instance in Kornai and Weibull (1983), or in Boycko, Shleifer and Vishny (1996), governments have 'parternalistic' or political behavior as they seek to protect or increase employment; in Shapiro and
} 
and/or because they do not provide appropriate incentives to firm managers. In particular, because governments lack the commitment not to bail out money-losing firms, public firms' managers tend to undertake money-losing projects. By hardening the firm's budget constraint, privatization helps restoring appropriate investment incentives (see Dewatripont and Maskin, 1995; Schmidt, 1996a and 1996b; Segal, 1998; Maskin, 1999). This theory has provided support to the possibility of productivity improvements through privatization reforms in transition economies and in the banking sector. Recent empirical evidence has suggested that privatization indeed improves the internal efficiency of firms. ${ }^{8}$ However, this literature has not addressed the important issue of allocative inefficiencies (price distortion) induced by privatization reforms in increasing returns to scale industries. Auriol and Picard (2008) is a first attempt to address the issue. Based on a linear demand model with asymmetric information on cost, these authors show that regulation of a natural monopoly can be dominated by laissez-faire for intermediate values of shadow costs of public funds. The present paper significantly enriches this result by allowing for a larger set of (ex-post) contracts, for a larger class of demand functions and for endogenous franchise fees. The decision to outsource is then altered with respect to Auriol and Picard (2008). In particular, ex-post contracting makes outsourcing desirable even for small shadow costs of public firms. Furthermore the combination of ex-post contracting and efficient bargaining over franchise fees always makes outsourcing a better policy than regulation. ${ }^{9}$

Thirdly our model can be related to the literature on public-private partnerships (PPP) that has merited recent attention in national and international funding institutions (see Vaillancourt Rosenau, 2000; IMF, 2004). The idea behind PPP is to make governments Willig (1990), governments are malevolent.

${ }^{8}$ Megginson and Netter (2001) in their literature review covering 65 empirical studies (some at the national level and some across countries) at the firm level conclude that in general private firms are more productive and more profitable than their public counterparts.

${ }^{9}$ The present model differs from "soft budget constraint" models as it relies neither on governments' lack of commitment nor on moral hazard. The model relies on the combination of adverse selection, firm's individual rationality constraint, and costly public funds. It nevertheless shares the same implication as "soft budget constraint" models that suggest to cut the subsidies to unproductive firms. 
purchase the service rather than the asset that is associated with the provision of a public good or of a good for which there is a potential market failure. On the one hand, PPPs are seen by governments as a vehicle to shift investment costs off their books and/or to safeguard the execution of projects that would otherwise hardly materialize given their budget constraints. On the other hand, PPPs are praised for their potential benefits in terms of productive efficiency. ${ }^{10}$

Finally the paper is related to the literature on mechanism design under type-dependent reservation utility (see Lewis and Sappington, 1989; Jullien, 2000; Picard, 2001; and Laffont and Martimort 2002, Chap. 3). Indeed the possibility of ex-post contracting involves type-dependent individual rationality constraint.

The paper is structured as follows. Section 2 describes the model. Section 3 and 4 characterize the optimal contracts under regulation and under outsourcing respectively. Section 5 analyzes the conditions under which outsourcing yields a higher welfare than regulation. Section 6 discusses the scope of the outsourcing contracts and some practical examples of outsourcing. Section 7 concludes.

\section{The Model}

The government has to decide whether a natural monopoly should be operated under public or private management. In line with Laffont and Tirole (1993), we call regulation regime the regime in which the government has control and cash-flow rights over a regulated firm. As it is standard in the regulation literature the government's control rights are associated with accountability on profits and losses. That is, it subsidizes the regulated firm in case of losses whereas it taxes it in case of profits. Such a combination of control rights and accountability duties by public authorities is typical of public ownership. In contrast, we call outsourcing the regime in which a private unregulated firm produce the commodity. Under outsourcing, control and cash-flow rights belong to a private

\footnotetext{
${ }^{10}$ Public-private partnerships (PPP) can be used to harden the firms' budget constraints as we discussed earlier and can be used to bundle complementary tasks such as the construction and the operation of infrastructure projects (see Hart 2003, Martimort and Pouyet 2006, Iossa and Martimort 2007).
} 
investor or, namely, a private firm. The government takes no responsibility for the firm's profits and losses. It can nevertheless ask the potential producer to pay a franchise fee for the right to operate as a monopoly. Moreover the government can contract ex-post with the firm to increase the supply of the commodity. We refer to this situation as ex-post contracting. When the government offers no ex-post contracts, the firm chooses the laissez-faire production level.

The paper focuses on natural monopoly. The firm needs to sink a fixed investment cost $K>0$ before the production period. ${ }^{11}$ To focus on the allocative efficiency problem and to keep the analysis simple, we assume that the investment cost $K$ is constant and is verifiable. ${ }^{12}$ The uncertainty lies on the impact of the investment on the technology. That is, after the investment stage, the firm incurs an idiosyncratic marginal cost $\beta$ to produce the output in quantity $Q$. We assume that the marginal cost $\beta$ is independently drawn from the support $[\underline{\beta}, \bar{\beta}]$ according to the density and cumulative distribution functions $g(\cdot)$ and $G(\cdot)$. The expectation operator is denoted $E$ so that $E[h(\beta)]=\int_{\underline{\beta}}^{\bar{\beta}} h(\beta) d G(\beta)$. For example, $\beta$ captures the uncertainty inherent to a $R \& D$ project. A larger variance corresponds to a more risky project. In the sequel, the terms 'ex-post' and 'ex-ante' correspond to the period before and after the realization of $\beta$.

To summarize, the firm cost function is as in Baron and Myerson (1982)

$$
C(\beta, Q)=K+\beta Q
$$

where $K$ is known in advance while $\beta$ is random.

Consumers are characterized by a decreasing inverse demand function, denoted $P(Q)$. The gross surplus associated with the consumption of $Q$ units of the commodity is defined as $S(Q)=\int_{0}^{Q} P(x) d x$. We focus on a commodity that generates a large enough surplus so that shutting down production is never optimal. Technically the willingness to pay

\footnotetext{
${ }^{11}$ This investment cost corresponds to the construction cost in infrastructure or utility projects (e.g., power plant, highway, water distribution network) or to research and development costs in projects like public health (e.g., a new medicine) or major ICT services for administrations (e.g., payroll management).

${ }^{12}$ This assumption simplifies the analysis by ruling out moral hazard issue about the optimal size of investment. For an analysis of the moral hazard issue see for instance Dewattripont and Maskin (1995).
} 
for the first unit of the good must be sufficiently large. This is formally stated in the following assumption:
A1

$$
P(0)>\bar{\beta}+G(\bar{\beta}) / g(\bar{\beta})
$$

Under assumption A1, public and private firms are always able to make a positive margin. Since investment costs are sunk, firms never shut down production. The firm's profit in the absence of public transfer is equal to $P(Q) Q-\beta Q-K$. The firm's profit with public transfer is equal to

$$
\Pi(\beta, Q, t, F)=P(Q) Q-\beta Q-K+t-F
$$

where $t$ is the ex-post transfer that the firm gets from the government and where $F$ is a possible ex-ante franchise fee paid to the government. The transfer to the firm can either be positive (i.e., a subsidy), or negative (a tax).

As in Laffont and Tirole (1993), the government is benevolent and utilitarian. It maximizes the sum of consumer's and producer's surpluses minus the social cost of transferring public funds to the firm. The government's objective function is

$$
W(\beta, Q, t, F, \lambda)=S(Q)-\beta Q-K-\lambda t+\lambda F
$$

where $\lambda$ is the shadow cost of public funds.

The shadow cost of public funds, $\lambda$, drives the results of the paper. This shadow cost, which can be interpreted as the Lagrange multiplier of the government budget constraint, measures the social cost of the government's economic intervention. For $\lambda$ close to 0 , the government maximizes the net consumer surplus; for larger $\lambda$, the government puts more weight on the social cost of transfers. The shadow cost of public funds is positive because transfers to regulated firms imply either a decrease in the production of public goods, such as schooling and health care, or an increase in distortionary taxation. Each euro that is transferred to the regulated firm costs $1+\lambda$ euros to society. In developed economies, $\lambda$ is mainly equal to the deadweight loss accrued to imperfect income taxation. It is assessed 
to be around 0.3 (Snower and Warren, 1996). ${ }^{13}$ In developing countries, low income levels and difficulties in implementing effective taxation programs are strong constraints on the government's budget, which leads to higher values of $\lambda$. In particular, the value is very high in countries close to financial bankruptcy. To fix idea the World Bank (1998) suggests a shadow cost of 0.9 .

We next compare regulation and outsourcing in the benchmark case of symmetric information between the firms and the government.

\section{Symmetric Information}

The timing under regulation is as follows. The government firstly decides whether or not to invest $K$; if $K$ is sunk, nature chooses the marginal cost $\beta$ according to the distribution function $G(\cdot)$; the regulated firm's manager and the government learn $\beta$; the government proposes a production and transfer scheme $\left(Q^{r}(\cdot), t^{r}(\cdot)\right)$. Because there is no ex-ante transfer of ownership under regulation, there is no payment of franchise fee $F$. Under symmetric information the government maximizes the utilitarian welfare function:

$$
\max _{\{Q(\cdot), t(\cdot)\}} E W=E[S(Q(\beta))-\beta Q(\beta)-K-\lambda t(\beta)]
$$

subject to the public manager's participation constraint: $\Pi[\beta, Q(\beta), t(\beta), 0]=0$. Pointwise maximization yields the following first order condition for $Q^{r}(\beta)$ :

$$
P(Q)+\frac{\lambda}{1+\lambda} P^{\prime}(Q) Q=\beta
$$

\footnotetext{
${ }^{13}$ The shadow cost of public funds $\lambda$ reflects the macro-economic constraints that are imposed on national governments' surpluses and debts levels by supranational institutions (e.g. by the Maastricht treaty on E.U. member states, by the I.M.F. on many developing countries). The shadow cost of public funds also reflects micro-economic constraints of government agencies that are unable to commit to long-term investment expenditures in their annual or pluri-annual budgets. In the context of privatepublic-partnership, the shadow cost of public funds reflects the short term opportunity gain to record infrastructure assets out of the government's book.
} 
The transfer is equal to $t^{r}(\beta)=-P\left(Q^{r}\right) Q^{r}+\beta Q^{r}+K$. The government subsidizes moneylosing firms if $t^{r}>0$ and it taxes profit-making firms if $t^{r}<0$. Ex-ante welfare writes as $E W^{r}=E\left[S\left(Q^{r}\right)+\lambda P\left(Q^{r}\right) Q^{r}-(1+\lambda) \beta Q^{r}-(1+\lambda) K\right]$.

Under outsourcing, the timing is as follows. First, a private investor chooses to enter the market by paying the franchise fee $F$ and by investing $K$. If the private firm enters, then nature chooses the marginal cost $\beta$ according to the distribution $G(\cdot)$. Under symmetric information the private firm's manager and the government learn $\beta$. The government then proposes a set of contracts $\left\{t^{o}(\cdot), Q^{o}(\cdot)\right\}$. The firm either chooses to pick a contract and to implement its terms, or it chooses not to contract with the government in which case it sets its production at the laissez-faire monopoly level. Production, exchange and transfer occur as agreed upon.

Once entered, the firm's fallback position is the laissez-faire equilibrium. After the realization of $\beta$, the private monopoly maximizes its variable profit $(P(Q)-\beta) Q$. The first order condition yields the laissez-faire monopoly levels of production $Q^{m}(\beta)$, which solves

$$
P(Q)+P^{\prime}(Q) Q=\beta .
$$

We denote

$$
\Pi^{m}(\beta)=\left[P\left(Q^{m}(\beta)\right)-\beta Q^{m}(\beta)\right]-K
$$

the monopoly profit. Since it is not optimal to let private monopoly operate at the laissezfaire level, the government can offer ex-post transfers to correct the monopoly price.

After the cost realization, the government proposes an ex-post contract that maximizes $E W=E[S(Q(\beta))-\beta Q(\beta)-K-\lambda t(\beta)]$ subject to the participation constraint of the private owner: $(P(Q)-\beta) Q+t(\beta) \geq\left(P\left(Q^{m}\right)-\beta\right) Q^{m}$. The reservation profit of the private owner is equal to his/her laissez-faire profit, which is type dependent and decreases with marginal $\operatorname{cost} \beta$. However, the reservation profit is independent of the output $Q$ chosen by the government. As a consequence, the outsourcing government chooses an output level that is exactly equal to the output under regulation: $Q^{o}(\beta)=Q^{r}(\beta)$. Regulation and outsourcing then differ only in term of transfers given to the firm. Under outsourcing, the 
government gives the smallest transfer that satisfies the participation constraint of the private owner. The transfer can be computed as $t^{o}=\left(P\left(Q^{m}\right)-\beta\right) Q^{m}-\left(P\left(Q^{r}\right)-\beta\right) Q^{r}$, which simply reimburses the difference between the (variable) profits under laissez-faire and regulation. Because $Q^{m}$ is the maximizer of the firm's variable profit, the transfer $t^{o}$ is positive for any cost realization $\beta$. Finally, since the private owner just gets his/her ex-post reservation (variable) profit $\left(P\left(Q^{m}\right)-\beta\right) Q^{m}$, he/she values his/her entry in the business to $E \Pi^{m}-F=E\left[\left(P\left(Q^{m}\right)-\beta\right) Q^{m}\right]-K-F$.

Before the cost realization, the risk neutral private investor accepts to pay the franchise fee $F$ if and only if $E \Pi^{m}-F \geq 0$. Given that $Q^{o}=Q^{r}$, the ex-ante welfare under outsourcing is then equal to $E W^{o}=E\left\{S\left(Q^{r}\right)+\lambda P\left(Q^{r}\right) Q^{r}-(1+\lambda) \beta Q^{r}-K-\lambda\left(P\left(Q^{m}\right)-\right.\right.$ $\left.\beta) Q^{m}+\lambda F\right\}$. Outsourcing yields a larger ex-ante welfare than regulation if and only if $E W^{o} \geq E W^{r}$. This is equivalent to

$$
\lambda\left[K-\left(P\left(Q^{m}\right)-\beta\right) Q^{m}+F\right] \geq 0 \Longleftrightarrow \lambda\left(F-E \Pi^{m}\right) \geq 0
$$

The cost and benefit of outsourcing can be broken down into the three basic elements that distinguish it from regulation: timing, outside option and franchise fee. ${ }^{14}$ First, by allowing the firm to make the investment and to become its residual claimant, the government saves on the social cost of the investment $\lambda K$. Second, by contracting ex-post with the private firm and by allowing it to earn a monopoly laissez-faire rent, the government constrains itself on the possible ex-post revenues it can tap from it. This has a social cost equal to $\lambda\left(P\left(Q^{m}\right)-\beta\right) Q^{m}$. Finally, the government is able to recoup ex-ante a franchise fee, which has a social benefit equal to $\lambda F$. Adding these three elements together, the reader readily observes that the social net benefit of outsourcing is proportional to the ex-ante loss of the private firm $F-E \Pi^{m}$. Therefore, under symmetric information, the government and the private firm cannot simultaneously gain from outsourcing. Outsourcing is at best equivalent to regulation either if the shadow cost of public funds $\lambda$ is zero or if the government is able to tap the whole ex-ante surplus profit through the franchise fee. We collect this result in the following proposition.

\footnotetext{
${ }^{14}$ We thank an anonymous referee for suggesting this useful decomposition.
} 
Proposition 1 Under symmetric information, outsourcing does not yield a higher welfare than regulation.

Proposition 1 is a reminiscence of the standard result in regulation theory stating that a benevolent and fully informed government cannot perform worse than the market since it is always able to replicate the market outcome. The above proposition goes behind this statement: the regulated firm does not perform worse than the market even though the government has instruments to correct ex-post the possible price distortions under outsourcing. The next section shows that this result is not robust under the more realistic assumption of asymmetric information.

\section{Asymmetric Information}

Under asymmetric information, the government is not able to acquire the information about firms' cost conditions. The timing of regulation and outsourcing is the same as in Section 3 except that cost realization $\beta$ is now the firms' private information. The government proposes a contract that entices firms to reveal their private information. We sequentially discuss the cases of regulation and outsourcing, whose variables will also be denoted by superscripts $r$ and $o$ without risk of confusion. The analysis of regulation replicates the standard mechanism design literature as it is presented in Baron and Myerson (1982) and Laffont and Tirole (1993). The analysis of outsourcing is somewhat more interesting as it involves the design of incentive contracts under type-varying participation constraint. A consequence of this peculiarity is that some firms are not offered a contract by the government.

\subsection{Regulation}

Under asymmetric information, the government proposes a production and transfer scheme $\left(Q^{r}(\cdot), t^{r}(\cdot)\right)$ that entices the regulated firm to reveal its private information. By the revelation principle, the analysis can be restricted to direct truthful revelation mechanism where the firm reports its true cost $\beta$. To avoid the technicalities of 'bunching', we make 
the classical monotone hazard rate assumptions (see Guesnerie and Laffont, 1984; Jullien, 2000):

\section{A2}

$$
G(\beta) / g(\beta) \text { and }(G(\beta)-1) / g(\beta) \text { are non decreasing. }
$$

Moreover in order to rule out corner solution in the sequel of the paper we focus on not too convex demand function. That is,

\section{A3}

$$
P^{\prime \prime}(Q) Q+P^{\prime}(Q)<0
$$

Because regulation implies no ex-ante transfer of ownership, the use of a franchise fee $F$ is irrelevant. Under asymmetric information the government maximizes the utilitarian welfare function:

$$
\max _{\{Q(\cdot), t(\cdot)\}} E W=E[S(Q(\beta))-\beta Q(\beta)-K-\lambda t(\beta)]
$$

subject to

$$
\begin{aligned}
(d / d \beta) \Pi(\beta, Q(\beta), t(\beta), 0) & =-Q(\beta) \\
(d / d \beta) Q(\beta) & \leq 0 \\
\Pi(\beta, Q(\beta), t(\beta), 0) & \geq 0
\end{aligned}
$$

Conditions (7) and (8) are the first and second order incentive compatibility constraints that entice the firm to reveal its private information $\beta$ truthfully. Condition (9) is the public manager's participation constraint. ${ }^{15}$ This problem is a standard adverse selection problem of regulation under asymmetric information (see Laffont and Tirole 1993). Under assumption A3 it admits an interior solution. The optimal output, denoted $Q^{r}(\beta)$, solves

$$
P(Q)+\frac{\lambda}{1+\lambda} P^{\prime}(Q) Q=\beta+\frac{\lambda}{1+\lambda} \frac{G(\beta)}{g(\beta)}
$$

Under assumption A2 the output $Q^{r}(\beta)$ is non increasing in $\beta$ so that condition (8) is satisfied. Comparing equation (10) with equation (3), one can check that the output

\footnotetext{
${ }^{15}$ The public manager's earnings are normalized to zero. Allowing a positive earning would reduce further the attractiveness of regulation compared to outsourcing.
} 
level under symmetric information is obtained by setting the term $G(\beta) / g(\beta)$ to zero. Because the LHS of (10) decreases in $Q$, we deduce that the output level under asymmetric information is lower than under symmetric information. In order to reduce the firm's incentive to inflate its cost report, the government requires high cost firms to produce less than it would do under symmetric information. The distortion increases with $\lambda$.

We next turn to the computation of the regulated firm's transfer. Integrating equation (7) while using equation (9) the firm's information rent is equal to

$$
\Pi^{r}(\beta)=\int_{\beta}^{\bar{\beta}} Q^{r}(\beta) d \beta
$$

The firm with the highest cost $\bar{\beta}$ gets zero information rent: $\Pi^{r}(\bar{\beta})=0$. More efficient firms get an informational rent. Substituting (11) into the definition of profit (1) yields the regulated firm's transfer

$$
t^{r}(\beta)=\int_{\beta}^{\bar{\beta}} Q^{r}(\beta) d \beta-\left[\left(P\left(Q^{r}(\beta)\right)-\beta\right) Q^{r}(\beta)-K\right]
$$

Larger investment costs raise the transfers to the regulated firm. The ex-ante welfare writes as

$$
E W^{r}=\int_{\underline{\beta}}^{\bar{\beta}}\left[S\left(Q^{r}(\beta)\right)-\beta Q^{r}(\beta)-K-\lambda t^{r}(\beta)\right] d G(\beta)
$$

The paper aims to study contracting arrangement that permits to deliver the commodity to consumers in the most efficient way. In what follow we study outsourcing as an alternative to regulation.

\subsection{Government Outsourcing}

Under outsourcing the firm is managed by a private investor or entrepreneur. The timing is the same as in the full information case, except that $\beta$ is now private information. This means that, the private firm firstly chooses to enter the market by paying the franchise fee $F$ and by investing $K$. If it enters, then nature chooses the marginal cost $\beta$ according to the distribution $G(\cdot)$. The private firm's manager learns $\beta$ while the government does not. As in the regulation case the government proposes a set of incentive compatible contracts 
$\left(t^{o}(\cdot), Q^{o}(\cdot)\right)$. The firm either chooses to commit with the government by picking a contract and by implementing its terms, or it chooses not to contract with the government, in which case it sets its production at the laissez-faire monopoly level. Production, exchange and transfers occur as agreed upon.

Under outsourcing, the firm's fallback position is given by its laissez-faire monopoly profit, $\Pi^{m}(\beta)$, which has been derived in Section 3. It is not necessarily optimal to let private monopoly operate at the laissez-faire level. The government may contract ex-post with the firm in order to avoid the welfare loss associated with monopoly pricing. In this case it subsidies the firm to produce more than its monopoly quantity. We firstly show that only a fraction of firms signs a contract with the government and secondly that the number of firms signing a contract decreases with the shadow cost of public funds.

\subsubsection{Selective ex-post contracts}

Let $Q^{o}(\beta)$ and $\Pi^{o}(\beta)$ denote the output and the profit of the private monopoly under ex-post contracting. After entry, the franchise fee is sunk. Since it plays no role in the quantity/price decision, we temporarily omit $F$. The government solves

$$
\max _{\{Q(\cdot), t(\cdot)\}} E W=E[S(Q(\beta))-\beta Q(\beta)-K-\lambda t(\beta)]
$$

subject to

$$
\begin{aligned}
(d / d \beta) \Pi(\beta, Q(\beta), t(\beta), 0) & =-Q(\beta) \\
(d / d \beta) Q(\beta) & \leq 0 \\
P(Q(\beta)) Q(\beta)-\beta Q(\beta)+t(\beta) & \geq P\left(Q^{m}(\beta)\right) Q^{m}(\beta)-\beta Q^{m}(\beta)
\end{aligned}
$$

Incentive compatibility constraints (14) and (15) are equivalent to (7) and (8). However, the private firm's participation constraint (16) differs from the participation constraint under regulation (9). Under ex-post contracting, the minimum profit acceptable to the firm is the operating profit it would get under laissez-faire. Subtracting $K$ on both sides of inequality (16), we can write the private firm's participation constraint more simply as

$$
\Pi(\beta, Q(\beta), t(\beta), 0) \geq \pi\left(\beta, Q^{m}(\beta)\right)
$$


Contrary to regulation, the firm's participation constraint (i.e., the RHS) now depends on its type $\beta$.

The government is obliged to leave large rents to low cost firms if it wants to contract with them. However it is not committed to compensate for the losses of high cost firms because private investors endorse the full responsibility of their investments. The government may then decide not to contract with high cost firms. This result is formally stated in the following lemma.

Lemma 2 Under Assumptions $A 1$ to A3 there exists a unique $\beta_{0} \in[\underline{\beta}, \bar{\beta}]$ such that $\beta_{0}=\min \left\{\beta_{0}^{\prime}, \bar{\beta}\right\}$ where $\beta_{0}^{\prime}$ solves the equation

$$
P\left[Q^{m}(\beta)\right]=\beta+\lambda \frac{G(\beta)}{g(\beta)}
$$

Output and profit of the firm under ex-post contracting are equal to

$$
\begin{aligned}
& Q^{o}(\beta)=\left\{\begin{array}{lr}
Q^{r}(\beta)>Q^{m}(\beta) & \text { if } \quad \beta<\beta_{0} \\
Q^{m}(\beta) & \text { if } \quad \beta \geq \beta_{0}
\end{array}\right. \\
& \Pi^{o}(\beta)=\left\{\begin{array}{lr}
\Pi^{m}\left(\beta_{0}\right)+\int_{\beta}^{\beta_{0}} Q^{r}(\beta) d \beta>\Pi^{m}(\beta) & \text { if } \quad \beta<\beta_{0} \\
\Pi^{m}(\beta) & \text { if } \quad \beta \geq \beta_{0}
\end{array}\right.
\end{aligned}
$$

Proof. See Appendix 1.

\section{INSERT FIGURE 1 HERE}

Figure 1 illustrates output and profit functions under regulation (thin curves), laissezfaire (dashed curves) and ex-post contracting (bold curves). Under regulation and ex-post contracting, low cost firms are enticed to claim larger subsidies by reporting higher cost levels. The government alleviates this problem by imposing smaller output levels to the firms that report high costs. Under regulation, the output distortion can be so strong that the high cost firms may produce less than under laissez-faire. That is, $Q^{r}(\beta) \leq Q^{m}(\beta)$ for all $\beta \geq \beta_{0}$. This does not occur under ex-post contracting because the fallback position 
of the government is the laissez-faire equilibrium. To understand this result consider the firm with $\beta=\beta_{0}$ so that $Q^{o}\left(\beta_{0}\right)=Q^{r}\left(\beta_{0}\right)=Q^{m}\left(\beta_{0}\right)$. There is no point to offer an ex-post contract to this firm: its output level is the government's preferred output level. Ex-post contracting and laissez-faire yield the same consumer and producer surpluses. Consider now a firm with $\beta>\beta_{0}$. If the government proposes an ex-post contract to this firm it is unable to get a surplus larger than under laissez-faire because incentive compatibility obliges it to distort output down to $Q^{r}(\beta)<Q^{m}(\beta)$. Moreover any transfer to this firm also increases the subsidies to all firms having smaller costs. Because the government is harmed by both effects, it offers no ex-post contract to firms with marginal cost $\beta$ larger than $\beta_{0}{ }^{16}$

By virtue of equation (17) we have $\beta_{0} \rightarrow \underline{\beta}$ when $\lambda \rightarrow \infty$. That is, for very large shadow costs of public funds, ex-post contracting is never optimal. Symmetrically, we can define $\lambda_{0} \geq 0$ as the shadow cost of public funds that yields the equality $\beta_{0}=\bar{\beta}$ :

$$
\lambda_{0}=g(\bar{\beta})\left[P\left(Q^{m}(\bar{\beta})\right)-\bar{\beta}\right]
$$

We deduce the following result.

Proposition 3 Let $\beta_{0}$ and $\lambda_{0}$ be defined equation (17) and (20).

(i) If $\lambda \leq \lambda_{0}$ all firms receive an ex-post contract under outsourcing $\left(\beta_{0}=\bar{\beta}\right)$.

(ii) If $\lambda>\lambda_{0}$ a fraction $G\left(\beta_{0}\right) \in(0,1)$ of firms receive an ex-post contract under outsourcing. This fraction decreases with $\lambda$ and tends to zero when $\lambda \rightarrow \infty$.

Since the shadow cost of public funds tends to decrease with a country's wealth, Proposition 3 suggests that ex-post contracting is more likely to occur in developed economies.

\footnotetext{
${ }^{16}$ Note that if assumption A3 was not imposed, the demand function may generate a profit function that is very convex for low $\beta$. The laissez-faire profit of a low cost firm could increase very rapidly as its cost falls. As a consequence, a firm with intermediate cost level could want to mimic a lower cost firm (instead of a higher cost firm). By doing so, this firm could claim to have high reservation profit and receive the large compensation that is granted to the lower cost firm. The government would then need to exclude low cost firms from the set of ex-post contracts. With type dependent participation constraints, exclusion can affect both very high and very low types simultaneously (see Jullien 2000, Proposition 2). For the sake of simplicity we rule out this case with Assumption A3.
} 
In developing countries outsourcing tends to take the extreme form of laissez-faire.

\subsubsection{Transfers}

We now study transfers under ex-post contracting. By the envelop theorem, we have $(d / d \beta) \Pi^{m}(\beta)=(\partial / \partial \beta)\left[P\left(Q^{m}(\beta)\right)-\beta\right] Q^{m}(\beta)=-Q^{m}(\beta)$. We deduce that

$$
\Pi^{m}(\beta)=\int_{\beta}^{\beta_{0}} Q^{m}(\beta) d \beta+\Pi^{m}\left(\beta_{0}\right)=\int_{\beta}^{\bar{\beta}} Q^{m}(\beta) d \beta+\Pi^{m}(\bar{\beta})
$$

Combining (21) with (19) into the definition of profit (1) we get

$$
t^{o}(\beta)=\left\{\begin{array}{lll}
\int_{\beta}^{\beta_{0}}\left[Q^{r}(\beta)-Q^{m}(\beta)\right] d \beta & \text { if } \quad \beta<\beta_{0} \\
+\left[P\left(Q^{m}(\beta)\right)-\beta\right] Q^{m}(\beta)-\left[P\left(Q^{r}(\beta)\right)-\beta\right] Q^{r}(\beta) & & \\
0 & \text { if } \quad \beta \geq \beta_{0}
\end{array}\right.
$$

By construction, the transfer $t^{o}(\beta)$ is non negative. On the one hand, high cost firms with $\beta \geq \beta_{0}$ receive no transfer. The difference between the transfer under expost contracting and regulation, $t^{o}(\beta)-t^{r}(\beta)$, is thus equal to $-t^{r}(\beta)$. This difference is positive if the government taxes the firm under regulation; it is negative if the government subsidizes it. On the other hand, low cost firms with $\beta<\beta_{0}$ receive a transfer that consists of two positive terms: an information rent (the first line in the expression of $t^{\circ}(\beta)$ ) and a subsidy to compensate for the fall in profits associated with the higher output levels prescribed in the ex-post contracts (the second line in the expression of $t^{o}(\beta)$ ). Since $t^{o}(\beta)$ involves a difference between profits under regulation and under laissez-faire, the terms with $K$ cancel out. Therefore, in contrast to regulation, the government does not compensate for the investment cost. The next lemma compares $t^{o}(\beta)$ with the transfer for regulated firms, $t^{r}(\beta)$, for low cost firms.

Lemma 4 Let $\Delta t(\beta)=t^{o}(\beta)-t^{r}(\beta)$. Then, for all $\beta<\beta_{0}$,

$$
\Delta t=\Pi^{m}\left(\beta_{0}\right)-\Pi^{r}\left(\beta_{0}\right)=\int_{\beta_{0}}^{\bar{\beta}}\left[Q^{m}(\beta)-Q^{r}(\beta)\right] d \beta+\Pi^{m}(\bar{\beta})
$$


Proof. See Appendix 2.

Expression (22) depends on threshold $\beta_{0}$ but not on the firm's type $\beta$. It includes the profit of the private firm $\Pi^{m}\left(\beta_{0}\right)$, which decreases with investment costs, and the rent of the public manager $\Pi^{r}\left(\beta_{0}\right)$, which, by (11), is independent of investment costs. Hence, larger investment costs decrease the level of transfers under ex-post contracting compared to regulation. Since $Q^{m}(\beta)>Q^{r}(\beta)$ for all $\beta>\beta_{0}$ (see Figure 1), the constant $\Delta t$ is positive if $\Pi^{m}(\bar{\beta})>0$. In this case the government pays larger transfers under ex-post contracting than it would under regulation. Some firms receive positive transfers whereas they would pay a tax under regulation (i.e., $t^{o}\left(\beta_{0}\right)=0>t^{r}\left(\beta_{0}\right)$ ). However, the result can be reversed if $\Pi^{m}(\bar{\beta})$ is sufficiently negative (i.e., $\Delta t$ can be negative). The government then pays smaller transfers under ex-post contracting than under regulation. Some firms receive no transfers whereas they would be subsidized under regulation (i.e., $\left.t^{o}\left(\beta_{0}\right)=0<t^{r}\left(\beta_{0}\right)\right)$.

\subsubsection{Welfare}

By Lemma 2, expected welfare under ex-post contracting writes as

$$
\begin{aligned}
E W^{o}(\lambda) & =\int_{\underline{\beta}}^{\beta_{0}} W\left(\beta, Q^{r}(\beta), t^{o}(\beta), F, \lambda\right) d G(\beta) \\
& +\int_{\beta_{0}}^{\bar{\beta}} W\left(\beta, Q^{m}(\beta), 0, F, \lambda\right) d G(\beta)
\end{aligned}
$$

Using expression (22), the linearity of the welfare function $W$ in $t$ and $F$ (see expression (2)), and using Lemma 4 , we rewrite the expected welfare function as

$$
\begin{aligned}
E W^{o}(\lambda) & =\int_{\beta_{0}}^{\bar{\beta}} W\left(\beta, Q^{m}(\beta), 0,0, \lambda\right) d G(\beta) \\
& +\int_{\underline{\beta}}^{\beta_{0}} W\left(\beta, Q^{r}(\beta), t^{r}(\beta), 0, \lambda\right) d G(\beta)-\lambda \Delta t G\left(\beta_{0}\right)+\lambda F
\end{aligned}
$$

The ex-ante welfare consists of four elements: the welfare accrued to private firms with high cost $\beta$ receiving no ex-post contract, the welfare accrued to private firms with low $\operatorname{cost} \beta$ that contract with the government to produce the regulated level output, the 
social cost of leaving the additional rent $\Delta t$ to the fraction $G\left(\beta_{0}\right)$ of firms under ex-post contract, and finally the social value of the franchise fee.

The next section discusses the optimal choice between regulation and outsourcing. ${ }^{17}$

\section{Regulation Versus Outsourcing}

To facilitate the welfare comparison, we change the integration boundaries in expression (24) so that we can write

$$
\begin{aligned}
E W^{o}(\lambda) & =\int_{\beta_{0}}^{\bar{\beta}}\left[W\left(\beta, Q^{m}(\beta), 0,0, \lambda\right)-W\left(\beta, Q^{r}(\beta), t^{r}(\beta), 0, \lambda\right)\right] d G(\beta) \\
& +E W^{r}(\lambda)-\lambda \Delta t G\left(\beta_{0}\right)+\lambda F
\end{aligned}
$$

Outsourcing is preferred to regulation if and only if $E W^{o}(\lambda)-E W^{r}(\lambda)>0$. Using again the linearity of $W$ in $t$, this condition is equivalent to:

$$
\left.\begin{array}{l}
\int_{\beta_{0}}^{\bar{\beta}}\left[W\left(\beta, Q^{m}(\beta), 0,0, \lambda\right)-W\left(\beta, Q^{r}(\beta), 0,0, \lambda\right)\right] d G(\beta) \\
+\lambda\left[F+\int_{\beta_{0}}^{\bar{\beta}} t^{r}(\beta) d G(\beta)-\Delta t G\left(\beta_{0}\right)\right]
\end{array}\right\}>0
$$

The difference in welfare between outsourcing and regulation is broken down into two effects: the economic surplus effect (the first line of (26)), and the fiscal effect (the second line of (26)). The fiscal effect is decomposed into three terms: the social value of the franchise fee, $\lambda F$, the social value of the reduction in subsidies to regulated firm, $\lambda \int_{\beta_{0}}^{\bar{\beta}} t^{r}(\beta) d G(\beta)$, and the social cost of additional rents to private firms under outsourcing, $\lambda \Delta t G\left(\beta_{0}\right)$. The sum of these three terms reflects the net saving in public funds that outsourcing generates compared to regulation. The economic surplus effect is new. Under outsourcing, low cost firms produce the same quantity than regulated firms but high cost firms' produce more (i.e., they produce the laissez-faire output). Higher production in high cost realizations does not only raise consumer surplus but it also increases producer surplus because high cost regulated firms produce below their monopoly optimal level.

\footnotetext{
${ }^{17}$ There is no need to compare laissez-faire with regulation. Ex-post contracting always dominates it.
} 
In what follows we show that the range of parameters for which outsourcing dominates regulation is not empty. It turns out difficult to characterize the outsourcing decision for all values of shadow costs of public funds without making specific assumptions about the demand function and the cost distribution. Therefore, we firstly focus on the simpler cases of small and large shadow costs of public funds. We then discuss the impact of franchise fees on the outsourcing decision. Finally we present the full characterization of the outsourcing decision in the case of linear demand and uniform cost distribution.

\subsection{Small shadow costs of public funds}

According to Proposition 3, the government offers an ex-post contract to all firms when $\lambda \leq \lambda_{0}$. By (20), this is equivalent to set $\beta_{0}=\bar{\beta}$. Since $\Pi^{r}(\bar{\beta})=0$ and $G(\bar{\beta})=1$, we deduce that $\Delta t G\left(\beta_{0}\right)=\Pi^{m}(\bar{\beta})$. The transfers under outsourcing are larger by an amount equal to the laissez-faire profit in the worst cost realization. Moreover, by virtue of Lemma 2, the quantities produced under regulation and under outsourcing are the same when $\beta_{0}=\bar{\beta}$. The economic surplus effect vanishes as the integral in expression (25) cancels out. So, the choice between the two structures depends only on the fiscal effect. More specifically, the ex-ante welfare is equal to

$$
E W^{o}(\lambda)=E W^{r}(\lambda)+\lambda\left(F-\Pi^{m}(\bar{\beta})\right)
$$

We deduce the following result.

Proposition 5 For $\lambda \leq \lambda_{0}$ outsourcing is preferred to regulation if and only if $F>$ $\Pi^{m}(\bar{\beta})$.

It is instructive to break down the condition of Proposition 5 into the elements that distinguish outsourcing from regulation, namely the timing, the franchise fee and the outside option. First, the government saves the social cost of the investment $\lambda K$. Second, it recoups a franchise fee for a social value of $\lambda F$. Finally, when $\lambda \leq \lambda_{0}$, the social cost of the outside option under outsourcing is equal to the social value of the lowest profit under laissez-faire, $\lambda\left[P\left(Q^{m}(\bar{\beta})\right)-\bar{\beta}\right] Q^{m}(\bar{\beta})$. Indeed, under outsourcing, the government gives 
to the private firm a rent that includes an information rent, $\int_{\beta}^{\bar{\beta}} Q^{r}(\beta) d \beta$, on top of a compensation for lowest outside option, $\left[P\left(Q^{m}(\bar{\beta})\right)-\bar{\beta}\right] Q^{m}(\bar{\beta})$. Under regulation, the government gives the same information rent to the regulated firm, but it does not offer any additional compensation to the public firm's manager because her outside option is zero. ${ }^{18}$ Therefore, the social cost of the outside option under outsourcing is equal to the lowest profit level under laissez-faire. When this value is positive, firms receive larger rents under outsourcing than under regulation. The reverse is true: when the lowest profit level is negative, firms receive lower rents under outsourcing because the government is able to avoid the social cost of subsidizing them in the worst cost realization.

Proposition 5 offers a sharp characterization of the optimal industrial policy. For low values of shadow costs of public funds, which are more likely to be found in developed countries, ${ }^{19}$ outsourcing is optimal as soon as the franchise fee collected by the government is larger than the worst realization of laissez-faire profit. In particular, because $E \Pi^{m}>\Pi^{m}(\bar{\beta})$, the government should outsource if the economic activity can be franchised at its expected market price, $F=E \Pi^{m}$. This point contrasts with Proposition 1, which established that, under symmetric information, the government is at best indifferent between regulation and outsourcing if $F=E \Pi^{m}$. More interestingly, even if the government is not able/allowed to raise a franchise fee, it should outsource as long as the firm make a loss with positive probability (i.e., $\Pi^{m}(\bar{\beta})<0$ ). In developed economies, increasing returns to scale industries subjected to large technical uncertainty are then good targets for outsourcing and ex-post contractual arrangement.

\subsection{Large shadow costs of public funds}

When the shadow cost of public funds is very large, private firms are never offered any ex-post contracts. That is, $\beta_{0} \rightarrow \beta$ if $\lambda \rightarrow \infty$. The condition (26) then becomes equivalent to $F+\int_{\underline{\beta}}^{\bar{\beta}} t_{\infty}^{r}(\beta) d G(\beta)>0$ where $t_{\infty}^{r}(\beta)=\lim _{\lambda \rightarrow \infty} t^{r}(\beta)$. We get the following result.

\footnotetext{
${ }^{18}$ Note again that assuming a strictly positive outside option would only favor the outsourcing regime.

${ }^{19}$ For instance, the shadow cost of public funds is assessed to about 0.3 in OECD countries while the threshold $\lambda_{0}$ is larger than 0.5 in the linear demand and uniform distribution example (see Section 5.4).
} 
Proposition 6 When $\lambda \rightarrow \infty$, outsourcing is preferred to regulation if and only if $F>$ $-E\left[t_{\infty}^{r}(\beta)\right]$.

The interpretation of Proposition 6 is straightforward. When the shadow cost of public funds is very large, the government puts an (infinitesimal) small weight on consumer surplus and therefore focuses on extracting the maximal revenue from the regulated or private firms. Outsourcing is preferred to regulation if and only if the government is able to recoup more revenues through an ex-ante franchise fee than what it can extract from a regulated firm through ex-post transfers. Note that when the government is not able/allowed to collect a franchise fee (i.e. $F=0$ ), Proposition 6 simply states that outsourcing is preferred as soon as the government expects to subsidize the regulated firm. The government abandons unprofitable markets to private investors and does not intervene any longer.

Additional intuition can be obtained by breaking down the condition of Proposition 6 into the three elements that differentiate outsourcing from regulation. Indeed we can write $\lambda\left\{F+E\left[t_{\infty}^{r}(\beta)\right]\right\}>0$ as

$$
\lambda\left\{F+K+E\left[\int_{\beta}^{\bar{\beta}} Q_{\infty}^{r} d \beta\right]-E\left[\left(P\left(Q_{\infty}^{r}\right)-\beta\right) Q_{\infty}^{r}\right]\right\}>0
$$

where $Q_{\infty}^{r}(\beta)=\lim _{\lambda \rightarrow \infty} Q^{r}(\beta)$. As before, with outsourcing the government collects the proceeds of the franchise fee (i.e. the first term), and it saves the social cost of the investment (i.e. the second term). More interestingly, the government also gets the opportunity to cut the subsidies that it expects to pay to the regulated firm; that is, the information rent (i.e. the third term) minus the firm's expected operational profit (i.e. the last term). This decomposition makes clear that, for large costs of public funds, the government does not care much about consumer surplus. ${ }^{20}$ It is not interested in correcting production levels so that it never contracts ex-post with the private firm. Outsourcing is thus socially valuable for high franchise fees, for large fixed costs and for expectations of large subsidies to the regulated firm.

\footnotetext{
${ }^{20}$ Indeed, one can readily show that the regulated output $Q_{\infty}^{r}(\beta)$ is equal to $Q^{m}(\beta+G(\beta) / g(\beta))$, which is smaller than the laissez-faire monopoly output $Q^{m}(\beta)$.
} 


\subsection{Franchise fees}

In this section, we study the role played by franchise fees in the outsourcing decision. We first study the outsourcing decision when franchise fees are set exogenously. Let us denote by $E \Pi_{0}^{o}$ the monopoly's expected profit when no franchise fee is asked. It corresponds to the maximal franchise fee that a risk-neutral private investor will ever agree to pay. Using (19) and (21), we know that the profit under outsourcing is equal to the profit under laissez-faire plus a positive information rent that is equal to $\int_{\beta}^{\beta_{0}}\left[Q^{r}(z)-Q^{m}(z)\right] d z$ for each firm with $\beta<\beta_{0}$. Using (11) and (12), this information rent can be written as $\Pi^{r}(\beta)-\Pi^{r}\left(\beta_{0}\right)-\left[\Pi^{m}(\beta)-\Pi^{m}\left(\beta_{0}\right)\right]$, which, by $(22)$, is equal to $\Pi^{r}(\beta)-\Pi^{m}(\beta)+\Delta t$. Hence, the ex-ante profit with zero franchise fee is equal to

$$
\begin{aligned}
E \Pi_{0}^{o} & =E \Pi^{m}+\int_{\underline{\beta}}^{\beta_{0}} \int_{\beta}^{\beta_{0}}\left[Q^{r}(z)-Q^{m}(z)\right] d z d G(\beta) \\
& =E \Pi^{m}+G\left(\beta_{0}\right) \Delta t+\int_{\underline{\beta}}^{\beta_{0}}\left[\Pi^{r}(\beta)-\Pi^{m}(\beta)\right] d G(\beta)
\end{aligned}
$$

We add $\lambda E \Pi_{0}^{o}$ on both sides of condition (26). After some substitutions and simplifications (see Appendix 3), the necessary and sufficient condition (26) becomes

$$
\lambda\left[E \Pi_{0}^{o}-F\right]<\left\{\begin{array}{l}
\lambda \int_{\underline{\beta}}^{\bar{\beta}} \Pi^{r}(\beta) d G(\beta) \\
+\lambda \int_{\beta_{0}}^{\bar{\beta}}\left[\Pi^{m}(\beta)-\left[P\left(Q^{r}(\beta)\right)-\beta\right] Q^{r}(\beta)+K\right] d G(\beta) \\
+\int_{\beta_{0}}^{\bar{\beta}}\left[W\left(\beta, Q^{m}(\beta), 0,0, \lambda\right)-W\left(\beta, Q^{r}(\beta), 0,0, \lambda\right)\right] d G(\beta) .
\end{array}\right.
$$

Outsourcing is preferred to regulation if and only if the LHS is lower than the RHS. The RHS includes the expected value of the public manager's information rent (first term), the additional profit (second term) and the additional surplus (third term) that high cost firms generate under outsourcing. It is straightforward to check that each term is positive. Indeed we have that $E \Pi^{r}(\beta) \geq 0$ and that $\Pi^{m}(\beta)=\max _{Q}[P(Q)-\beta] Q-K \geq$ $\left[P\left(Q^{r}(\beta)\right)-\beta\right] Q^{r}(\beta)-K$. Finally the economic surplus effect is always positive because $Q^{m}(\beta) \geq Q^{r}(\beta)$ for $\beta \geq \beta_{0}$ and because welfare is a decreasing function of output for this range of parameters (indeed, both $Q^{m}(\beta)$ and $Q^{r}(\beta)$ are smaller than the output under symmetric information as shown in equation (3)). We deduce the following result. 
Proposition 7 If the franchise fee $F$ is sufficiently close to $E \Pi_{0}^{o}$, outsourcing is preferred to regulation for any shadow cost of public funds $\lambda>0$.

\section{Proof. See Appendix 3}

This proposition contrasts with Proposition 1 stating that regulation is always the best policy under the symmetric information. Here outsourcing is strictly preferred to regulation for any shadow cost of public funds if the government is able to tap a large enough share of the ex-ante profit through the franchise fee. This is likely to occur when the number of investors is large, when they do not collude and when there exist no information asymmetry at the ex-ante stage. These conditions corresponds to perfectly efficient procurement and financial markets. Moreover the possibility to successfully auction public projects to private investors and entrepreneurs strongly depends on the government's ability to commit not to expropriate them once investments are sunk. This ultimately depends on the credibility and on the stability of the political and judicial institutions. Efficient financial markets, strong legal system and credible governments are found in developed economies. Such institutions are lacking in developing countries where attracting private investors is difficult. In such countries, governments might be unable to tap a large amount of private firms' ex-ante profits. They might thus prefer regulation. ${ }^{21}$

Finally it is worth emphasizing that outsourcing can be preferred when the government is not able/allowed to collect a positive franchise fee (i.e. when $F=0$ ). From condition (29), this situation arises when the private firm expects low profits and when the government expects high information rents and strong output distortions in the regulated firm. If profitability is low it is even possible that the government pays an up-front subsidy $(F<0)$ to the private firm to entice it to enter and take the business risk. This is likely to occur with large investment cost. Indeed the LHS of (29) decreases with $K$ (through the term $E \Pi^{m}$ in $E \Pi_{0}^{o}$ ) while the RHS is independent of it. Everything else being equal, higher investment costs increases the benefits of outsourcing.

In the above discussion, we have considered exogenous franchise fees. However Propo-

\footnotetext{
${ }^{21}$ In contrast, strong moral hazard issues, time inconsitency and lack of governments' economic focus can be rationales for privatization in least developed countries (see Kornai et al. 2002).
} 
sition 7 shows that there is always room for negotiation as there always exists a franchise fee that is accepted by the private investor and that makes the government prefer outsourcing. The negotiation should nevertheless be efficient in the sense that no economic opportunities are lost during the bargaining process. This is formally stated in the following corollary.

Corollary 8 Outsourcing is always preferred to regulation when the franchise fee $F$ is endogenously determined by an efficient bargaining process.

To clarify this result, let assume that the franchise fee is the Nash solution of the bargaining process. The Nash bargaining solution is ${ }^{22}$

$$
F^{\phi}=\phi E \Pi_{0}^{o}-(1-\phi)\left[E W_{0}^{o}(\lambda)-E W^{r}(\lambda)\right] / \lambda
$$

where $E W_{0}^{o}(\lambda)$ is $E W^{o}(\lambda)$ evaluated at $F=0$ and $\phi \in[0,1]$ is the government's bargaining power. The franchise fee $F^{\phi}$ can be positive or negative. It will be negative when the government has weak bargaining power (i.e., when $\phi$ is close to zero) and/or when expected profits are negative. When the market is not profitable the government is willing to help a firm to enter. It subsidizes the sunk cost and proposes ex-post contracts. The franchise fee will also be negative when the welfare level under regulation is sufficiently small compared to the welfare level under outsourcing without franchise fee. In this situation the firm is able to extract an ex-ante rent from the government because it knows that the option of regulation is not very attractive.

The results of this section rest on two key assumptions: first, risk neutral investors have access to efficient financial markets and second, the government does not auction the right to run the regulated firm to potential public managers. This last assumption is usually justified by the fact that information rents take the form of in-kind benefits that

\footnotetext{
${ }^{22}$ The firms's payoff is $E \Pi_{0}^{o}-F$ and its fallback position is 0. The government's welfare is decomposed into the social benefit of the franchise fee $\lambda F$ and $E W_{0}^{o}(\lambda)=E W^{o}(\lambda)-\lambda F$. Its fallback position is regulation that yields $E W^{r}(\lambda)$. The Nash bargaining allocation solves $\max _{F}\left[E W_{0}^{o}(\lambda)+\lambda F-E W^{r}(\lambda)\right]^{\phi}\left[E \Pi_{0}^{o}-F\right]^{1-\phi}$ where $\phi \in[0,1]$ is the government's bargaining power.
} 
are difficult to trade. Assume, for the sake of the argument, that the government is able to perfectly auction the right to operate a public-regulated firm to some risk neutral manager. The government is then able to recoup the manager's expected rents, $\int_{\underline{\beta}}^{\bar{\beta}} \Pi^{r}(\beta) d G(\beta)$. The ex-ante welfare associated with regulation is increased by this amount. This is equivalent to cancel the first term in (29). Proposition 7 is still valid. Outsourcing is preferred to regulation for any franchise fee $F$ that is sufficiently close to $E \Pi_{0}^{o}$. The crucial assumption of the paper is thus the existence of efficient financial markets. Here again policy implications are more likely to fit developed economies.

\subsection{Linear example}

We have shown in Section 5.1 that outsourcing is preferred to regulation when the shadow cost of public funds is lower than the threshold $\lambda_{0}$ and when the firm makes a loss with a positive probability. The practical relevance of this result depends on the value of $\lambda_{0}$. In addition, the above results suggest that outsourcing is more valuable for large investment costs $K$ (i.e., for low profitability market) and for large uncertainties about variable costs $\beta$. We assess the relevance of these ideas by characterizing the outsourcing decision in the case of linear inverse demand function $P(Q)=a-b Q(a>0$ and $b>0)$ and a uniform distribution of cost $\beta$ that, without loss of generality, takes values in the interval $[0, \bar{\beta}] .{ }^{23}$ As a result, $G(\beta)=\beta / \bar{\beta}$, and the hazard rate $G(\beta) / g(\beta)=\beta$ so that assumption A1 simplifies to $a \geq 2 \bar{\beta}$ whereas assumption A2 is always satisfied. Assumption A3 always holds with linear demand functions. It is straightforward to check that equation (17) yields $\beta_{0}=a /(1+2 \lambda)$ and equation $(20)$ yields $\lambda_{0}=(a-\bar{\beta}) /(2 \bar{\beta})$ so that $\lambda_{0} \in[1 / 2,+\infty) .{ }^{24}$ The shadow cost of public funds is assessed to be around 0.3 in industrial countries (see for instance Snower and Warren, 1996). We conclude that if demand and cost functions can reasonably be approximated by linear functions and satisfy assumption A1, which is

\footnotetext{
${ }^{23}$ With a linear demand, setting $\underline{\beta}$ larger than zero is equivalent to rescaling the intercept $a$ to $a-\underline{\beta}$.

${ }^{24}$ Let consider a risky project so that $a=2 \bar{\beta}$ and $\lambda_{0}=1 / 2$. If the government chooses outsourcing, all private firms receive an ex-post contract if $\lambda \leq 1 / 2$. If $\lambda>1 / 2$, the fraction of private firms that contract ex-post with the government is equal to $G\left(\beta_{0}\right)=2 /(1+2 \lambda)$. For instance at $\lambda=0.9,71 \%$ of the firms get an ex-post contract and at $\lambda=2$, only $40 \%$ receive it.
} 
an empirical issue, the threshold $\lambda_{0}$ lies above the range of the shadow costs prevailing in developed economies. It then seems plausible that outsourcing dominates regulation in rather risky business in OECD countries.

Let $V \equiv E\left[\left(P\left(Q^{m}\right)-\beta\right) Q^{m}\right]=\left(3 a^{2}-3 \bar{\beta} a+\bar{\beta}^{2}\right) /(12 b)$ be the expected variable profit of a laissez-faire monopoly (i.e., so that $E \Pi^{m}=V-K$ ). Appendix 4 shows that the welfare difference between regulation and outsourcing, $E W^{r}-E W^{o}$, is fully determined by the parameters $V, \lambda$ and $F+K$.

Proposition 9 Suppose that the demand is linear so that $P(Q)=a-b Q$ and that the cost is uniformly distributed over $[0, \bar{\beta}]$ so that $a \geq 2 \bar{\beta}$. Then, there exist two thresholds $\left(m_{0}, m_{1}\right), 3 / 7<m_{0}<m_{1}<1$, such that

(i) outsourcing is never preferred to regulation if $(K+F) / V<m_{0}$.

(ii) outsourcing is always preferred to regulation if $(K+F) / V \geq m_{1}$.

(iii) otherwise, there exists a unique threshold $\lambda_{1}\left(\lambda_{1}>\lambda_{0}\right)$ such that outsourcing is preferred to regulation if and only if $\lambda \leq \lambda_{1}$.

In addition, outsourcing is more likely to be preferred if $\bar{\beta}$ increases (i.e. $m_{0}$ and $m_{1}$ decreases and $\lambda_{1}$ increases with larger $\bar{\beta}$ ).

Proof. See Appendix 4.

Proposition 9 shows that outsourcing is more likely to be preferred to regulation for lower shadow costs of public funds (smaller $\lambda$ ), for lower profitability (higher $K / V$ ratio) and for larger cost spreads (larger range $[0, \bar{\beta}]$ ). To illustrate this proposition, Figure 2 depicts the relative levels of investment costs, $K / V$, above which outsourcing is preferred to regulation. The first panel presents the case of a zero franchise fee $(F=0)$ whereas the second panel presents the case of a franchise fee equal to half the ex-ante laissez-faire profit $\left(F=E \Pi^{m} / 2=(V-K) / 2\right)$. Curves are drawn for various cost spreads $[0, \bar{\beta}]$ where $\bar{\beta}$ is equal to $0.10 * a / 2,0.20 * a / 2, \ldots$ and $a / 2$.

\section{INSERT FIGURE 2 HERE}


We have already shown Section 5.3 that outsourcing is preferred to regulation when the government is able to tap a large franchise fee from the monopoly. However, as illustrated in Figure 2, this result is still robust when the government cannot extract a franchise fee from the private sector. In other words, the outsourcing result does not hinge on the government ability to collect franchise fees. It hinges on the existence of regulation costs, captured here by information rents. Indeed, outsourcing is dominated for all values of investment costs and for all costs of public funds when the cost spread tends to zero $(\bar{\beta} \rightarrow 0=\underline{\beta})$. So, when there is no informational rent, regulation is optimal. ${ }^{25}$

\section{Discussion}

The paper has presented the conditions under which benevolent and utilitarian governments prefer to outsource a non-competitive economic activity to a private investor. This section focuses on the economic content of these normative results. We first illustrate the results by discussing different outsourcing cases according to their business contexts. We study next the scope of the formal outsourcing contracts. We show that they can be interpreted more broadly to include PPPs.

\subsection{Outsourcing in practice}

This paper shows that outsourcing is preferred for small shadow costs of public funds (i.e., for rich countries). The non competitive activities that are more likely to yield a social benefit if outsourced involve large cost spreads, i.e. large business risk, or relatively low profitability (i.e., a relatively high $K / V$ in Figure 2). It is worth noting that historically the earlier outsourcing contracts involved risky businesses such as exploration and

\footnotetext{
${ }^{25}$ One can thus check the continuity of the model as a function of the business risk under the uniform cost distribution. Since $g(\beta)=1 / \bar{\beta}$ tends to infinity when the cost spread vanishes, $\lambda_{0}$ also tends to infinity so that all firms get subsidized. Proposition 5 hence applies and it is easily checked that $E W^{o}(\lambda)-E W^{r}(\lambda) \geq \lambda\left[F-\Pi^{m}(0)\right]$, which corresponds to the condition in Proposition 1.
} 
war. ${ }^{26}$ In very poor countries outsourcing takes the extreme form of laissez-faire. These results have policy implications about ownership structure and contractual arrangements in existing industries. We explore some of them in what follows.

Large business risk: A sector which has traditionally been organized with the type of ex-post contractual arrangement described in the paper is the pharmaceutical industry. It is a high-technology industry where the largest firms spend heavily on R\&D (i.e., in the US about $10 \%$ of their sales revenues according to the National Science Foundation, $17 \%$ according to the industry). The patent system confers a natural monopoly structure on each niche of the industry. Yet, despite the monopoly structure and the safety and externality concerns attached to drugs production and distribution, the pharmaceutical industry is mostly owned and managed privately. A major difference between this industry and other increasing-return-to-scale industries, such as public utilities, is uncertainty. Of 10000 pharmaceutical products patented, only 10 are marketed (OECD, 2000). With such a low rate of success, the paper shows that it is optimal for governments to contract ex-post with the private sector rather than to endorse ex-ante the full responsibility of the investments through regulation or public ownership. The private firms have accordingly much freedom in setting the prices of their patented products, while consumers' access to them is subsidized. ${ }^{27}$ The classification between reimbursed and non-reimbursed drugs is consistent with the optimal outsourcing scheme. Only efficient types lead to ex-post contractual agreement between the health insurances and the firms so that consumption is higher than under laissez-faire. Less efficient drugs are left to the market. ${ }^{28}$

\footnotetext{
${ }^{26}$ For instance Queen Isabella of Spain outsourced exploration of the Western Ocean to an Italian contractor in 1492; The British contracted for Hessian mercenaries to fight in America War of Independance (see Savas 2005). Privateers are another example of contracting out of war at sea.

${ }^{27}$ In some countries, such as Germany, Norway, Finland, United-States or Canada, prices are free. In the US pharmacies are unregulated and it is legal to purchase pharmaceutical via the internet. In other ones, such as Australia, Belgium, France or Italy, prices of prescribed drugs are negotiated (but not regulated) by government agencies because they are covered by public insurance. In average OECD countries more than three-quarters of pharmaceutical expenditure is reimbursed in some way, usually by a mix of public and private insurance, except in North-America (Jacobzone 2000).

${ }^{28} \mathrm{In}$ practice there is a limit of outsourcing of risky projects because private firms are liable to default
} 
Low profitability: The analysis illuminates that outsourcing is socially beneficial for activities that have a relatively low profitability (i.e., a relatively high $K / V$ ). This result suggests that outsourcing to the private sector of money-losing public services, such as public services in low density areas, might be efficient. In remote, rural area the maximal ex-ante franchise fee a private firm is willing to pay is generally negative (i.e., it is a subsidy). The government is willing to contract out with the private sector as soon as the subsidy it requires for the service is lower than the loss of running it publicly. Examples include postal services outsourced to grocery stores and to gas stations in Sweden, and in New Zealand. At the EU level most postal operators have hence been restructuring their networks. They have usually closed the least profitable offices and replaced them by franchised of retail outlets (see Nera 2004). Another example is public transportation outsourced to local taxi companies in rural France (e.g. in Calvados, in Haute-Garonne), in Switzerland (e.g., Geneva area), or in Canada (e.g. at Salaberry-deValleyfield, or Victoriaville). For public transportation the EU commission has provided subsidies to finance the development of such "taxibus" services (Commission Européenne 2007). The type of contractual arrangements between the local government and the private taxi companies is very close to the optimal ex-post contract derived in the paper. The taxis get a public subsidy so that their profit is higher than under laissez-faire; the users pay a modest fee (i.e., usually the price of a bus ticket). These outsourcing solutions in low density areas are by far more cost and quality effective than standard public transportation.

High franchise fees: Outsourcing is preferred to regulation for any shadow cost of public funds if the government is able to tap a large enough share of the ex-ante profit through the franchise fee. This might offer an explanation about the outsourcing policy of water management in large French cities. Indeed in France water management in big and bankruptcy. This is illustrated by the many cost overruns, delays and terminations in outsourced public sector information and communication technologies (ICT) contracts in the UK (the fourth public outsourcing area, see Kable, 2007). The social benefit of outsourcing is compromised when the canceled service or commodity is crucial to the government. The impact of firms bankruptcy on optimal outsourcing contract is left for future research. 
cities is often outsourced to private companies in exchange of fees. Some cities, such as Toulouse in 1990, have hence been able to liquidate their debt by contracting out their water. $^{29}$

Very poor countries: In very poor countries, governments are entirely focused on tax collection. Since they cannot afford to subsidize private firms, outsourcing always takes the extreme form of laissez-faire. It is chosen as soon as the ex-ante franchise fee paid by the private sector is higher than the value of the expected transfers that can be extracted expost from the public regulated firm. Consistent with our theory, utility services provision is more market oriented in very poor countries than in OECD countries. For instance, in Sub Saharan Africa, water and electricity services to the middle class and the poor are often offered by private entreprises that are ready to invest to provide such services without any subsidy (see Auriol and Blanc, 2008). Similarly transportation services in African capital cities is almost entirely left to the private (informal) sector. Unregulated minibuses and/or motorcycles organized in corporations (to control the routes and the tarifs) are filling the service gap left by the public sector without any subsidy (Kumar and Barrett, 2008). In light of the financial constraint faced by most African governments, it is second best to let private providers serve freely the less profitable markets. Outsourcing is even Pareto improving when it leads to the creation of an infrastructure or a service that would have not existed otherwise. By contrast privatization of public firms' profit centers is suboptimal. In practice they have proven to be fiscally costly and highly unpopular.

\subsection{Outsourcing contracts and PPPs}

In this paper, outsourcing contracts have been assumed to be quite restricted in terms of the details set out at the ex-ante stage. Before entry and investment, the government and the firm commit to a contract with only two items: a franchise fee to be paid up-

\footnotetext{
${ }^{29}$ In 1990 the Compagnie Générale des Eaux (Veolia), paid some FF 500 millions to the city of Toulouse, in addition to the FF 770 millions of debt of the public water operator, in exchange of the city water concession. In 1995 a law was passed to ban entry fee in water concessions after several scandals of corruption. Entry fees have since been replaced by annual renting fees.
} 
front by the private investor and an ownership statement which implicitly makes void any future claim by the government on the market outcome and structure. It is only after the realization of the investment that the government eventually comes and reneges about the market outcome by offering a more detailed ex-post contract or subsidy scheme.

There is however a second interpretation to our outsourcing contracts. Indeed, nothing precludes the government to write the details of the future (state dependent) contract or subsidy scheme within the initial contract that it signs with the outsourcing firm. The detailed ex-ante contract includes three items: a franchise fee, a clause about the firm's unconditional right to operate in the market and a detailed description of a set of payments contingent on the realization of output and/or technological uncertainties. Such a contract is renegotiation-proof because, by the way it is designed, neither parties find it profitable to make Pareto-improving offers after the realization of the private firm's entry and investment. The complexity of this initial contract resembles that of actual contracts involved in public-private-partnerships (PPP) where much details are laid down before the investment decision of the private party. ${ }^{30}$ In PPPs the private partner is supposed to acquire or create an asset as well as to bear a significant share of the risk associated with it in exchange for control and cash-flow rights (i.e. ownership). As recognized by the literature, the transfer of some risk to the private partner is essential to create incentives to behave efficiently (see Glaister, 1999). In addition, such transfer of risk is also consistent with the accounting rules used by monitoring institutions. For example, Eurostat, the Statistical Office of the European Communities, classifies the assets involved in publicprivate-partnerships as non-government assets on the condition that the private partner bears the construction risk, and either availability or demand risk (Eurostat, 2004). This is precisely the line of modeling that we propose in this paper where the private firm bears the full risk of its investment. The government is able to correct the market outcome either ex-post by the use of subsidies or ex-ante by the writing of a detailed initial contract. To

\footnotetext{
${ }^{30}$ In 1992, John Major's government introduced the Private Finance Initiative (PFI), which aimed at encouraging PPPs in the United Kingdom. The main focus of the program was on reducing the public sector borrowing requirement, at least from official public records. Later on, Tony Blair's government shifted the emphasis of the PFI program to the achievement of "value for money".
} 
sum up, the essence of the outsourcing decision lies in the transfer of control and cash-flow rights to a private investor, not in the level of details of the ex-ante contract. Ex-ante contracts can be as straightforward as simple statements of transfer of franchise fee and ownership or, equally, they can involve additional details about state contingent output levels as in PPPs.

\section{Conclusion}

The paper studies a model of natural monopoly. A benevolent government maximizes a utilitarian welfare function under adverse selection. We compare two regimes. In the regulation regime, a public manager runs the firm's operation. Because of information rents, the government is not able to implement the first best solution. In the outsourcing regime, the government abandons the control and cash-flow rights to a private entrepreneur who freely chooses its price and its output levels. The essence of the outsourcing decision hence lies in the transfer of control and cash-flow rights to a private investor. In the absence of government intervention this yields the monopoly laissez-faire solution. The government can however propose ex-post contracts to increase production. The expost contracts need to leave the private firm with at least its laissez-faire profit. We show that the government chooses to offer ex-post contracts to low cost firms only. They are subsidized to achieve the output level under regulation. In contrast, high cost firms do not receive any contract. They operate under laissez-faire whenever it yields a higher output than regulation. In practice the government is able to correct the market outcome either ex-post by the use of subsidies or ex-ante by the writing of a detailed initial contract as in public-private-partnerships.

Outsourcing generates two types of benefits. First, it prevents the government from subsidizing money-losing firms. By the same token it forbids the government to tap revenues from profitable ones. It also yields franchise fees that are extracted ex-ante. Second it relaxes incentive compatibility constraint, which requires to reduce the output of high cost firms. The importance of those benefits on the outsourcing decision depends 
on the value of the shadow cost of public funds. When it is low, fiscal issues are not important. The welfare function is tilted toward the consumer and producer surplus. Outsourcing is then always preferred as long as the franchise fee is larger than the worst laissez-faire profit. For larger values of the shadow cost of public funds outsourcing is preferred if the franchise fee is large enough.

These normative results provide a useful grid to analyze outsourcing decisions and public-private-partneships in practice. In advanced economies they suggest that outsourcing is more cost effective to deliver high technology products, such as pharmaceutical products. They also suggest that outsourcing is more cost effective to cover low profitability market segments of public utilities, such as postal or transportation services in low density areas. In very poor countries, outsourcing, which takes the extreme form of laissez-faire, is optimal in low profitability segments of natural monopolies. This is in contrast to profitable segments that should be under public control.

Finally, we analyze a class of models with uniform cost distribution and linear demand functions and we show that outsourcing dominates regulation for a large set of economic parameters. Asymmetric information and governments' financial constraint are important costs for public management. These costs add to the internal efficiency costs analyzed in the privatization literature and suggest that outsourcing is in many cases a better policy than public ownership and regulation.

\section{References}

AURIOL E. and LAFFONT J.J. (1993) "Regulation by Duopoly", Journal of Economics 86 Management Strategy, vol 1, issue 3, 507-533.

AURIOL E. and BLANC A. (2008), "Capture and Corruption in Public Utilities: The Cases of Water and Electricity in Sub-Saharan Africa", forthcoming Utilities Policy.

AURIOL E. and PICARD P.M. (2008) "Privatizations in Developing Countries and the Government's Budget Constraint"forthcoming in the World Bank Economic Review.

BARON D. and MYERSON R. (1982), "Regulating a Monopolist with Unknown 
Costs", Econometrica, 50, 911-930.

BOYCKO M., SHLEIFER A. and VISHNY R. (1996), "A Theory of Privatization", Economic Journal, 106, 309-19.

Commission Européenne (2007), "Des relations en pleine croissance, une Europe en pleine croissance", Quatrième rapport sur la cohésion économique et sociale, ISBN 92-7905708-3, Communautés européennes.

DANA, J. and SPIER K. (1994), "Designing a Private Industry: Government Auctions with Endogenous Market Structure", Journal of Public Economics, 53, 127-147.

DEWATRIPONT M. and MASKIN E. (1995), "Credit and Efficiency in Centralized and Decentralized Economies, Review of Economic Studies, 62(4), 541-56.

EUROSTAT (2004) Eurostat Press Office, February 11, 2004.

GLAISTER S. (1999) Past Abuse and Future Uses of Private Finance and Public Private Partnership in Transport, Public Money and Management, CIPFA, 29-36.

GUESNERIE R. and LAFFONT J.J. (1984), "A Complete Solution to a Class of Principal-Agent Problems with Application of the Control of Self-Managed Firms", Journal of Public Economics, 25, 329-69.

IOSSA E. and MARTIMORT, D. (2007), "The Economics of Public Private Partnerships", mimeo TSE.

JACOBZONE S. (2000), "Pharmaceutical Policies in OECD Countries: Reconciling Social and Industrial Goals", OECD occasional papers, DEELSA/ ELSA / WD(2000)1.

JULLIEN B. (2000), "Participation Constraints in Adverse Selection Models", Journal of Economic Theory, 93, 1-47.

KABLE (2006), "UK public sector outsourcing - the big picture to 2008-09", published by KABLE

KORNAI J. and WEIBULL W. (1983), "Paternalism, buyers' and sellers' market", Mathematical Social Sciences, 6(2), 153-169.

KUMAR A. and BARRET F. (2008), "Stuck in Traffic: Urban Transport in Africa", report for the Africa Infrastructure Country Diagnostic (AICD) project, the World Bank group. 
LAFFONT, J.J. and TIROLE J. (1986), "Using cost observation to regulate firms", Journal of Political Economy, 94: 614-641.

LAFFONT, J.J. and TIROLE J. (1993), A Theory of Incentives in Procurement and Regulation, MIT press.

LAFFONT, J.J. and TIROLE J. (1991), "Privatization and Incentives", Journal of Law, Economics and Organization, 6, 1-32.

LAFFONT J.J. and MARTIMORT D. (2002), The Theory of Incentives, Princeton University Press.

MARTIMORT, D. and J. POUYET (2006), "Build it or not: Normative and Positive Theories of Public Private Partnerships", CEPR Discussion Paper No. 5610.

McGUIRE T. and RIORDAN M. (1995), "Incomplete Information and Optimal Market Structure: Public Purchases from Private Providers", Journal of Public Economics, $56,125-141$.

MASKIN E. (1999), "Recent Theoretical Work on the Soft Budget Constraint", American Economic Review, 89(2), 421-25.

MEGGINSON W. and NETTER J. (2001): "From State to Market: A Survey of Empirical Studies on Privatization", Journal of Economic Literature, 39, 321-89.

NERA (2004), "Economics of Postal services: final report" A Report to the European Commission DG-MARKT Prepared by NERA, Economics Consulting, London, http://www.nera.com

NEWBERRY D. M. and POLLIT M.G. (1997), "The Restructuring and Privatisation of the UK electricity supply- was it worth it?" Public sector policy for the Private Sector. The World Bank Group.

OECD (2000), "Competition and Regulation issues in the Pharmaceutical Industry", DAFFE/CLP(2000)29.

PICARD, P.M. 2001, "Job Additionality and Deadweight Spending in Perfectly Competitive Industries", Journal of Public Economics 79 (3): 521-41.

PFIZER JOURNAL (2003), "Public and Private Funding in the Quest for New Cures", vol VII, Number 3. 
SAVAS, E. S. (2005), Privatization in the City: Successes, Failures, Lessons, Washington, DC: CQ Press.

SCHMIDT K. (1996-a), "The Costs and Benefit of Privatization- An Incomplete Contracts Approach", Journal of Law, Economics and Organization, 12, 1-24.

SCHMIDT K. (1996-b), "Incomplete Contracts and Privatization, European Economic Review, 40, 569-580.

SEGAL I (1998), "Monopoly and Soft Budget Constraint, Rand Journal of Economics, 29(3), 569-609.

SHAPIRO C. and WILLIG R. (1990), "Economic Rationale for the Scope of Privatization", DP 41, Princeton University.

SNOWER A. and WARREN R. (1996), "The Marginal Welfare Cost of Public Funds: Theory and Estimates", Journal of Public Economics, 61, 289-305.

VAILlanCOURT ROSEnAU P. (2000): PublicPrivate Policy Partnerships. MIT Press, Cambridge.

WORLD BANK (1998), "World Development Indicators".

\section{Appendix 1: Proof of Lemma 2}

The proof is an application of Jullien (2000) in the particular case of common value adverse selection. We make it here explicit the dynamic programming approach. The program can be written as

$$
\max _{Q(\cdot), \Pi(\cdot), \mu(\cdot), \gamma(\cdot)} \int_{\underline{\beta}}^{\bar{\beta}} H_{1}(\beta, Q, \Pi, \mu, \gamma) d \beta
$$

where

$$
\begin{aligned}
H_{1}(\beta, Q, \Pi, \mu, \gamma) & =[S(Q)+\lambda P(Q) Q-(1+\lambda) \beta Q-\lambda \Pi] g(\beta) \\
& +\mu(\dot{\Pi}+Q)+\lambda \gamma(\beta)\left(\Pi-\Pi^{m}(\beta)\right)
\end{aligned}
$$

where $\Pi^{m}(\beta) \equiv\left[P\left(Q^{m}(\beta)\right)-\beta\right] Q^{m}(\beta)-K$, where $\mu(\beta)$ is the co-state variable of the incentive constraint and where $\gamma(\beta) \geq 0$ is the Lagrange multiplier of the participation con- 
straint. After integrating by part, this is equivalent to $\max _{Q(\cdot), \Pi(\cdot), \mu(.), \gamma(.)} \int_{\underline{\beta}}^{\bar{\beta}} H_{2}(\beta, Q, \Pi, \mu, \gamma)$ $d \beta$ where

$$
\begin{aligned}
H_{2}(\beta, Q, \Pi, \mu, \gamma) & =[S(Q)+\lambda P(Q) Q-(1+\lambda) \beta Q-\lambda \Pi] g(\beta) \\
& -\dot{\mu}(\beta) \Pi+\mu(\beta) Q+\lambda \gamma(\beta)\left(\Pi-\Pi^{m}(\beta)\right)
\end{aligned}
$$

with transversality conditions: $\Pi(\underline{\beta}) \mu(\underline{\beta})=\Pi(\bar{\beta}) \mu(\bar{\beta})=0$. It is easy to check that concavity conditions are respected. So, the following first order conditions $\partial H_{2} / \partial \Pi=0$ and $\partial H_{2} / \partial Q=0$ are also sufficient:

$$
\begin{aligned}
\dot{\mu} & =\lambda(\gamma(\beta)-g(\beta)) \\
P(Q)+\frac{\lambda}{1+\lambda} P^{\prime}(Q) Q & =\beta-\mu(\beta)
\end{aligned}
$$

Integrating both sides of the first equality yields $\mu(\beta)=\lambda(\Gamma(\beta)-G(\beta))$ where $\Gamma(\beta)=$ $\int_{\underline{\beta}}^{\beta} \gamma(\beta) d \beta$. Since $\gamma \geq 0, \Gamma$ is a non decreasing function. By the transversality conditions, $\bar{\mu}(\underline{\beta})=\mu(\bar{\beta})=0$, which implies that $\Gamma(\underline{\beta})=0$ and $\Gamma(\bar{\beta})=1$. Using this result in the second equality gives

$$
P(Q)+\frac{\lambda}{1+\lambda} P^{\prime}(Q) Q=\beta+\frac{\lambda}{1+\lambda} \frac{G(\beta)-\Gamma(\beta)}{g(\beta)}
$$

By Assumption A2 the RHS increases in $\beta$ whereas the LHS decreases in $\beta$ by Assumption A3. Therefore the solution of (31) is a function $l(\beta, \Gamma)$ that is non increasing in $\beta$. Moreover, because the RHS decreases in $(31), l(\beta, \Gamma)$ is a non decreasing function of $\Gamma$ (see 'potential separation' in Jullien, 2000). The solution is displayed as the bold curve of Figure 3 .

\section{INSERT FIGURE 3 HERE}

Consider the binding participation constraint: $\Pi(\beta)=\Pi^{m}(\beta)$ and $\gamma(\beta)>0$. A necessary condition is that $\dot{\Pi}(\beta)=\dot{\Pi^{m}}(\beta)$ or, by the envelop theorem, $Q(\beta)=Q^{m}(\beta)$, which is equivalent to $l(\beta, \Gamma)=Q^{m}(\beta)$. 
We study the intersection of $Q^{m}(\beta)$ with $l(\beta, \Gamma)$ successively for $\Gamma=1$ and for $\Gamma=0$. On the one hand, using expression (4), we find that $l(\beta, 1)>Q^{m}(\beta)$. So, $l(\beta, 1)$ never intersects $Q^{m}(\beta)$ and, thus, $\Gamma(\beta)$ is never equal to 1 . On the other hand, if $l(\beta, 0)$ intersects $Q^{m}(\beta)$, it must intersect at some $\beta_{0}$ that satisfies both conditions (4) and (31), which yields the expression (17) that we write again here:

$$
P\left(Q^{m}\left(\beta_{0}\right)\right)-\beta_{0}=\lambda \frac{G\left(\beta_{0}\right)}{g\left(\beta_{0}\right)}
$$

Under Assumptions A2 and A3, this equality accepts a unique solution $\beta=\beta_{0}$. Indeed, by Assumption A2, the RHS of (32) increases in $\beta_{0}$. Also, note that the LHS of (32) is positive and decreases in $\beta_{0}$ iff $P\left(Q^{m}(\beta)\right)-\beta$ is a decreasing function, or by (4), iff $P^{\prime}\left(Q^{m}(\beta)\right) Q^{m}(\beta)$ is an increasing function. Since $Q^{m}$ is non increasing in $\beta$, this is true under Assumption A3: $P^{\prime \prime} Q+P^{\prime}<0$.

We thus have that, for $\beta<\beta_{0}$, the solution of the program is $Q^{o}(\beta)=l(\beta, 1)=Q^{r}(\beta)$ and $\gamma(\beta)=0$, and that, for $\beta \geq \beta_{0}, Q^{o}(\beta)=Q^{m}(\beta)=l(\beta, \gamma(\beta))$ and $\gamma(\beta)>0$. Also, one can check that $Q^{m}(\beta)>Q^{r}(\beta)$ iff $\beta>\beta_{0}$.

\section{Appendix 2: Proof of Lemma 4}

Let $\pi(\beta, Q) \equiv(P(Q)-\beta) Q-K$. For any $\beta<\beta_{0}$,

$$
\begin{aligned}
\Delta t & =t^{o}(\beta)-t^{r}(\beta) \\
& =\int_{\beta}^{\beta_{0}}\left[Q^{r}(\beta)-Q^{m}(\beta)\right] d \beta+\pi\left(\beta, Q^{m}(\beta)\right)-\pi\left(\beta, Q^{r}(\beta)\right) \\
& -\left[\int_{\beta}^{\bar{\beta}} Q^{r}(\beta) d \beta-\pi\left(\beta, Q^{r}(\beta)\right)\right] \\
& =\int_{\beta}^{\beta_{0}}\left[Q^{r}(\beta)-Q^{m}(\beta)\right] d \beta+\pi\left(\beta, Q^{m}(\beta)\right)-\int_{\beta}^{\bar{\beta}} Q^{r}(\beta) d \beta \\
& =\int_{\beta}^{\beta_{0}} Q^{r}(\beta) d \beta+\Pi^{m}\left(\beta_{0}\right)-\int_{\beta}^{\bar{\beta}} Q^{r}(\beta) d \beta \\
& =-\int_{\beta_{0}}^{\bar{\beta}} Q^{r}(\beta) d \beta+\Pi^{m}\left(\beta_{0}\right)=\Pi^{m}\left(\beta_{0}\right)-\Pi^{r}\left(\beta_{0}\right)
\end{aligned}
$$


where we used (21) in the third and fourth equalities and (11) in the last equality. This expression can be re-written as $\int_{\beta_{0}}^{\bar{\beta}}\left[Q^{m}(\beta)-Q^{r}(\beta)\right] d \beta+\Pi^{m}(\bar{\beta})$ where the first term is positive because $Q^{m}(\beta)>Q^{r}(\beta)$ for all $\beta>\beta_{0}$ (see proof of the Lemma 2 ).

\section{Appendix 3: Proof of Proposition 7}

We here detail the proof of condition $(29)$. Let $\pi(\beta, Q) \equiv(P(Q)-\beta) Q-K$. Adding $\lambda\left(E \Pi_{0}^{o}-F\right)$ on both sides of condition $(26)$ we get

$$
\left.\begin{array}{l}
-\lambda \Delta t G\left(\beta_{0}\right)+\lambda E \Pi_{0}^{o}+\lambda \int_{\beta_{0}}^{\bar{\beta}} t^{r}(\beta) d G(\beta) \\
+\int_{\beta_{0}}^{\bar{\beta}}\left[W\left(\beta, Q^{m}(\beta), 0,0, \lambda\right)-W\left(\beta, Q^{r}(\beta), 0,0, \lambda\right)\right] d G(\beta)
\end{array}\right\}>\lambda\left(E \Pi_{0}^{o}-F\right)
$$

Replacing $E \Pi_{0}^{o}$ by it value in (28) and using the identity $\int_{\beta_{0}}^{\bar{\beta}} t^{r}(\beta) d G(\beta)=\int_{\beta_{0}}^{\bar{\beta}}\left[\Pi^{r}(\beta)-\right.$ $\left.\pi\left(\beta, Q^{r}(\beta)\right)\right] d G(\beta)$, the first line on the LHS becomes

$$
\lambda E \Pi^{m}+\lambda \int_{\underline{\beta}}^{\beta_{0}}\left[\Pi^{r}(\beta)-\Pi^{m}(\beta)\right] d G(\beta)+\lambda \int_{\beta_{0}}^{\bar{\beta}}\left[\Pi^{r}(\beta)-\pi\left(\beta, Q^{r}(\beta)\right)\right] d G(\beta)
$$

Adding the term $\lambda E \Pi^{r}-\lambda E \Pi^{m}-\lambda \int_{\underline{\beta}}^{\bar{\beta}}\left[\Pi^{r}(\beta)-\Pi^{m}(\beta)\right] d G(\beta)(=0)$, this expression becomes

$$
\lambda E \Pi^{r}+\lambda \int_{\beta_{0}}^{\bar{\beta}}\left[\Pi^{m}(\beta)-\pi\left(\beta, Q^{r}(\beta)\right)\right] d G(\beta
$$

which yields the condition (29).

\section{Appendix 4: Linear Example}

We consider the linear inverse demand function $P=a-b Q(a>0, b>0)$ and a uniform distribution of $\operatorname{cost} \beta$. Without loss of generality, we normalize $\underline{\beta}=0$ and for the sake of convenience, we define $\alpha=2 \bar{\beta} / a$ where $\alpha \in[0,1]$ is a parameter that indexes the spread of cost distribution. Under those assumptions, we get that $\lambda_{0}=(a-\bar{\beta}) /(2 \bar{\beta})=$ $(2-\alpha) /(2 \alpha)$ and that $V \equiv E\left[P\left(Q^{m}(\beta)\right)-\beta\right] Q^{m}(\beta)=\left(3 a^{2}-3 \bar{\beta} a+\bar{\beta}^{2}\right) /(12 b)=$ $\left(12-6 \alpha+\alpha^{2}\right) a^{2} /(48 b)$. So, the expected operational profit $V$ is proportional to $a^{2} / b$. 
One can readily show that expected welfare is also proportional to $a^{2} / b$. This allows us to simplify computations by normalizing the investment cost and the franchise fee such that $k=K / V$ and $f=F / V$. So, $E \Pi^{m} / V=1-k$. We compute that welfare under regulation is equal to

$$
\frac{E W^{r}}{V}=2 \frac{12(1+\lambda)^{2}+\alpha^{2}(1+2 \lambda)^{2}-6 \alpha(\lambda+1)(2 \lambda+1)}{\left(12-6 \alpha+\alpha^{2}\right)(1+2 \lambda)}-(1+\lambda) k
$$

and that welfare under outsourcing is equal to

$$
\frac{E W^{o}}{V}=\left\{\begin{array}{lll}
\frac{24+36 \lambda-12 \alpha(1+2 \lambda)+\alpha^{2}(\lambda+2)(1+2 \lambda)}{\left(12-6 \alpha+\alpha^{2}\right)(1+2 \lambda)}-k+\lambda f & \text { if } & \lambda<\lambda_{0} \\
\frac{8+3 \alpha\left(\alpha^{2}-6 \alpha+12\right)(2 \lambda+1)^{2}}{2 \alpha\left(12-6 \alpha+\alpha^{2}\right)(1+2 \lambda)^{2}}-k+\lambda f & \text { if } & \lambda \geq \lambda_{0}
\end{array}\right.
$$

Comparing those two expressions, we get that $E W^{o} \geq E W^{r}$ if and only if

$$
k+f \geq m(\lambda, \alpha) \equiv \begin{cases}m_{0} & \text { if } \quad \lambda<\lambda_{0} \\ m_{0}+\frac{\alpha^{4}}{12-6 \alpha+\alpha^{2}} \frac{\left(\lambda-\lambda_{0}\right)^{3}}{\lambda\left(\alpha\left(\lambda-\lambda_{0}\right)+1\right)^{2}} & \text { if } \quad \lambda \geq \lambda_{0}\end{cases}
$$

where $m_{0} \equiv 3(2-\alpha)^{2} /\left(12-6 \alpha+\alpha^{2}\right)$ lies in the interval $\left[\frac{3}{7}, 1\right]$. One can readily show that the second term in the last expression is an increasing function of $\lambda$ for $\lambda \geq \lambda_{0}$. Therefore $m(\lambda, \alpha)$ increases in $\lambda$ for $\lambda \geq \lambda_{0}$. Also, we note that $\lim _{\lambda \rightarrow \infty} m(\lambda, \alpha)=$ $m_{1} \equiv\left[3(2-\alpha)^{2}+\alpha^{2}\right] /\left(12-6 \alpha+\alpha^{2}\right)$, which is larger than $m_{0}$ and lies in the interval $\left[\frac{4}{7}, 1\right]$. As a result, the function $m(\lambda, \alpha)$ (weakly) increases with $\lambda$. So, we can readily conclude (i) that outsourcing is never prefered to regulation if $k+f<m_{0}$, (ii) that, if $k+f \in\left[m_{0}, m_{1}\right)$ there exists a unique threshold $\lambda_{1}\left(\lambda_{1}>\lambda_{0}\right)$, such that outsourcing is prefered to regulation if and only if $\lambda \leq \lambda_{1}$, and (iii) outsourcing is always prefered to regulation if $k+f \geq m_{1}$.

Finally, one can further show that $m_{0}$ and $m_{1}$ are decreasing functions of $\alpha$. In addition, for $\lambda \geq \lambda_{0}$, we get

$\frac{\partial}{\partial \alpha} m(\lambda, \alpha)=-12 \frac{\left(\begin{array}{c}4 \alpha^{2}\left(6-6 \alpha+\alpha^{2}\right)\left(\lambda-\lambda_{0}\right)^{3}+2 \alpha\left(36-36 \alpha+10 \alpha^{2}-\alpha^{3}\right)\left(\lambda-\lambda_{0}\right)^{2} \\ +2(6-\alpha)(2-\alpha)(3-\alpha)\left(\lambda-\lambda_{0}\right)+(6-\alpha)(2-\alpha)^{2} \alpha^{-1}\end{array}\right)}{\alpha^{2}\left(12-6 \alpha+\alpha^{2}\right)^{2}(1+2 \lambda)^{2} \lambda}$

which is negative because $\alpha \in[0,1]$. As a consequence, $m(\lambda, \alpha)$ is a decreasing function of $\alpha$. This means that outsourcing is more likely to be preferred if $\alpha$ increases; that is, if $\bar{\beta}$ increases. 

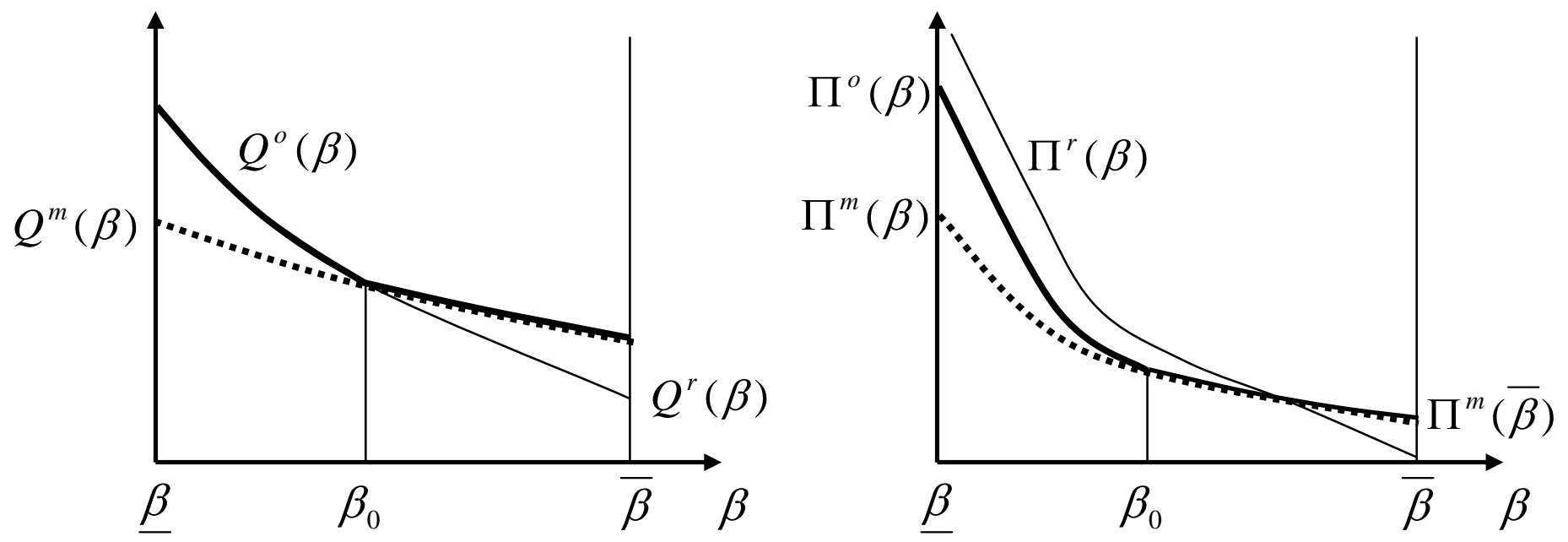

Figure 1: Output and Profit under Regulation, Laissez-Faire and Outsourcing. 


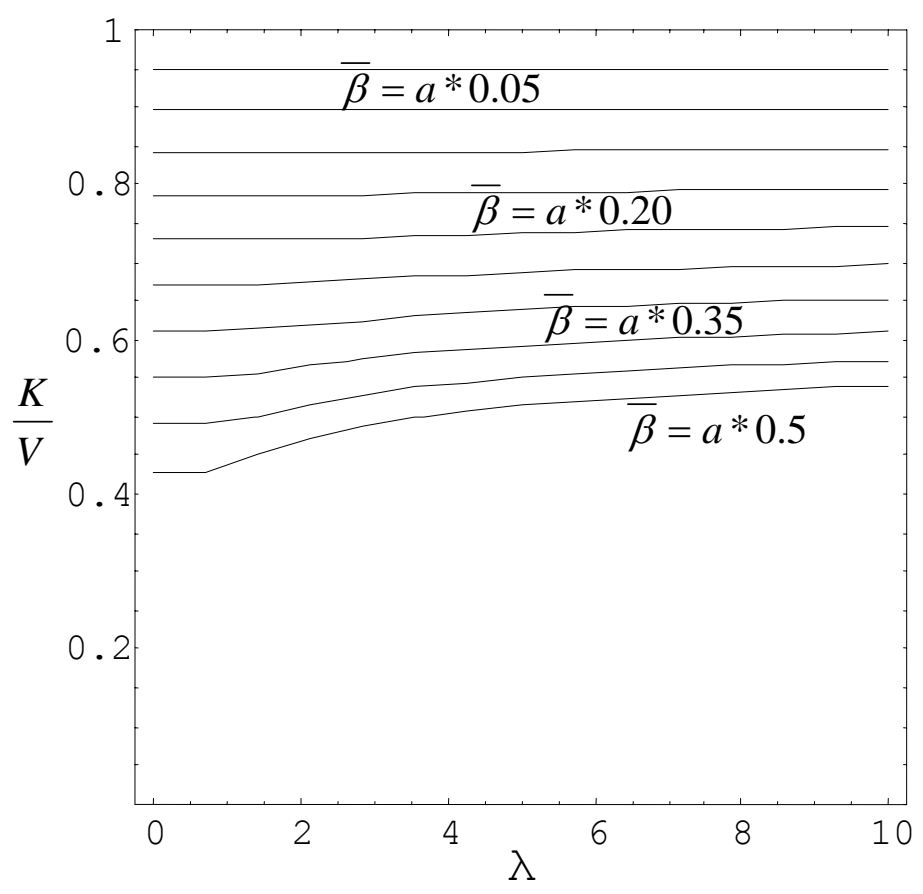

Franchise fee $\mathrm{F}=0$

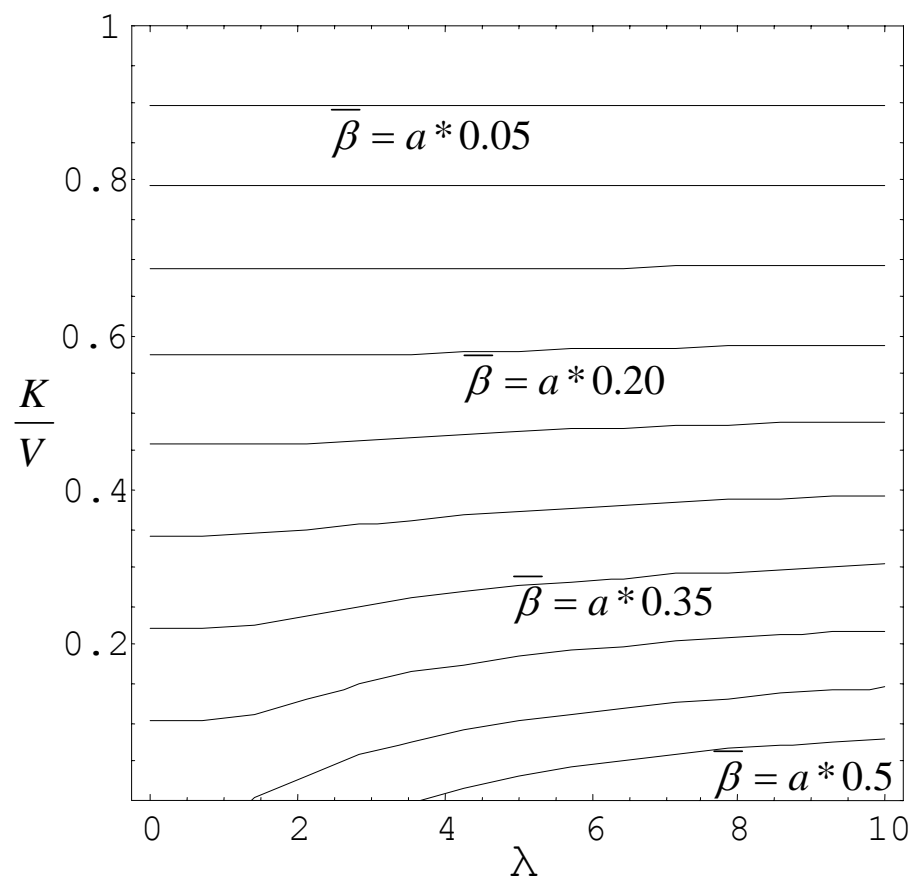

Franchise fee $\mathrm{F}=\mathrm{E} \Pi \mathrm{m} / 2$

Figure 2: Outsourcing v/s Regulation in the Linear Model 

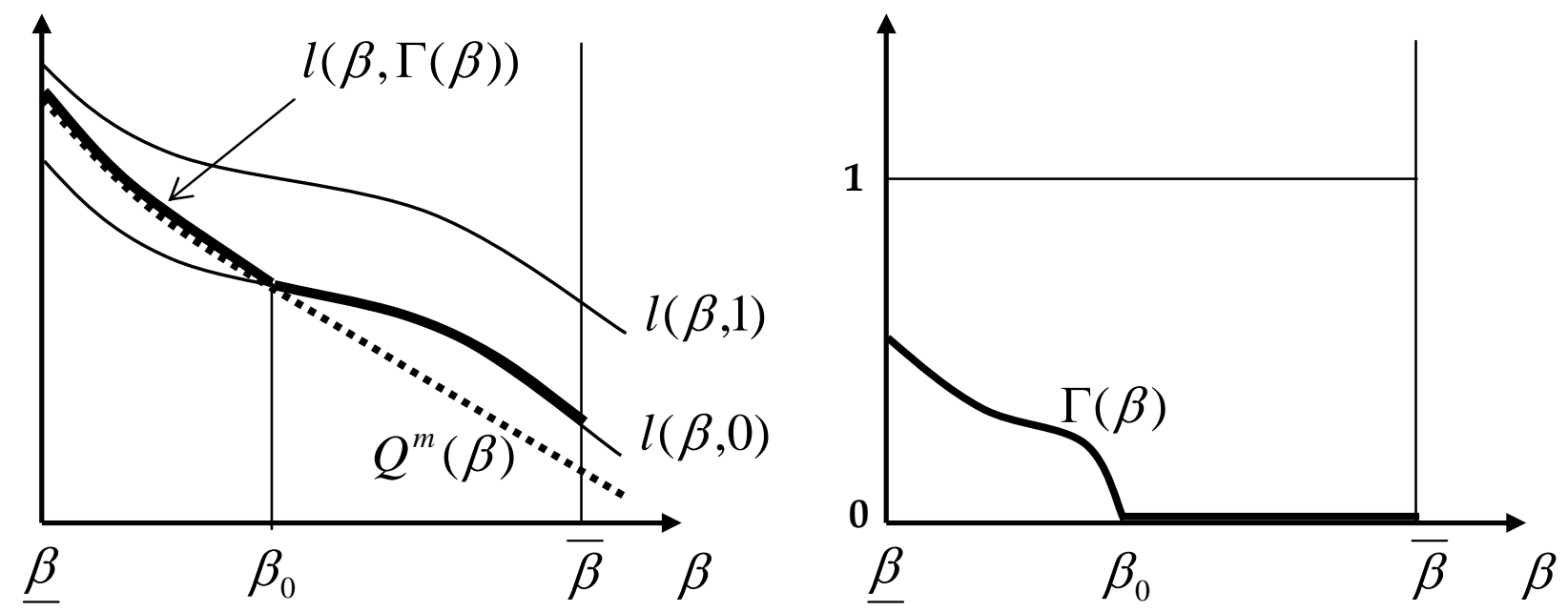

Figure 3: Output levels and shadow value of participation constraint $\Gamma(\beta)$ 